\title{
Influence of Boron Content on the Solidification Structure, Magnetic Properties and Hot Mechanical Behavior in an Advanced As-Cast TWIP Steel
}

A. E. Salas-Reyes ${ }^{1}, * \mathbb{C}$, G. Altamirano-Guerrero ${ }^{2} \mathbb{E}$, J. F. Chávez-Alcalá ${ }^{3}$, A. Barba-Pingarrón ${ }^{4} \mathbb{C}^{\text {, }}$ I. A. Figueroa ${ }^{5}{ }^{(0}$, A. M. Bolarín-Miró $\left.{ }^{6}{ }^{(}\right)$, F. Sánchez-De Jesús ${ }^{6}{ }^{\circ}$, R. Deaquino-Lara ${ }^{7}$ and A. Salinas ${ }^{7}$ (D)

1 Facultad de Química, UNAM, Departamento de Ingeniería Metalúrgica, Circuito de la Investigación Científica S/N, Coyoacán, Ciudad de Mexico 04510, Mexico

2 División de Estudios de Posgrado e Investigación, Tecnológico Nacional de Mexico/IT de Saltillo, Blvd. Venustiano Carranza 2400, Col. Tecnológico, Saltillo, Coahuila 25280, Mexico; galtamirano@itsaltillo.edu.mx

3 Instituto Politécnico Nacional, ESIQIE, Departamento de Ingeniería en Metalurgia y Materiales, Ciudad de Mexico 07738, Mexico; jfchavez@ipn.mx

4 Centro de Ingeniería de Superficies y Acabados (CENISA), Facultad de Ingeniería, UNAM, Circuito Exterior S/N, Ciudad Universitaria, Ciudad de Mexico 04510, Mexico; arbapin5@gmail.com

5 Instituto de Investigaciones en Materiales, Universidad Nacional Autónoma de Mexico (UNAM), Circuito Exterior S/N, Cd. Universitaria, Ciudad de Mexico 04510, Mexico; iafigueroa@unam.mx

6 Área Académica de Ciencias de la Tierra y Materiales, Universidad Autónoma del Estado de Hidalgo, Hidalgo 42184, Mexico; anabolarin@msn.com (A.M.B.-M.); fsanchez@uaeh.edu.mx (F.S.-D.J.)

7 Centro de Investigación y de Estudios Avanzados del Instituto Politécnico Nacional, Unidad Saltillo, Av. Industria Metalúrgica 1062, Parque Industrial Saltillo-Ramos Arizpe, Coahuila 25900, Mexico; rogelio.deaquino@cinvestav.edu.mx (R.D.-L.); armando.salinas@cinvestav.edu.mx (A.S.)

* Correspondence: enriquesalas@comunidad.unam.mx; Tel.: +52-55-5622-5243

Received: 7 August 2020; Accepted: 10 September 2020; Published: 12 September 2020

Abstract: This research work reports the effect of boron micro-additions (180 and $470 \mathrm{ppm}$ ) on the solidification structure, magnetic properties and hot ductility behavior of an advanced low-carbon highly alloyed twinning-induced plasticity (TWIP) steel. For this purpose, three experimental TWIP steels were fabricated by melting commercial raw materials and casting into metallic molds. Solidification structure was characterized by means of optical and scanning electron microscopy techniques, and a statistical study was carried out to measure dendrite features. A vibrating sample magnetometer was used, at room temperature, to determine magnetic properties, and a $\mathrm{X}$-ray diffraction analysis was performed in order to identify the related phases during magnetic measurements. Finally, the hot ductility in the as-cast condition was evaluated at 700,900 and $1100{ }^{\circ} \mathrm{C}$, under a constant strain rate of $0.001 \mathrm{~s}^{-1}$. The results indicate that boron micro-additions cause an overall refining solidification structure and austenitic grain size. However, as the boron content increases, segregation of this element promotes formation of ferrite and $\varepsilon$-martensite, leading to ferromagnetic behavior. Nonetheless, with subsequent hot- and cold-rolling, the single austenitic phase is achieved, and this behavior is eliminated. Hot tensile tests revealed that boron micro-addition is beneficial to the hot ductility behavior. The greatest influence was observed for the higher concentration of boron (470 ppm). In comparison with the steel without boron content, the reduction of area (RA) is more than the triple of the hot workability during straining at $900{ }^{\circ} \mathrm{C}$. Thus, present results demonstrate that boron micro-addition has an excellent potential for refining dendritic microstructure and improving the hot-deformation behavior of present low-carbon highly alloyed TWIP steel. 
Keywords: TWIP steel; boron micro-addition; incoherent solidification; dendritic structure; ferromagnetic behavior; hot ductility

\section{Introduction}

The industrial applications of advanced high-strength steels (AHSS) have a continuous tendency to grow thanks to their superior mechanical properties. The use of microalloying elements in the fabrication of AHSS is a common operative practice because of their effect in the resulting microstructure and mechanical behavior. High-Mn austenitic twinning-induced plasticity (TWIP) steels are one of the emerging high-strength steel grades that have shown a high level of potential in the automobile engineering, due to their extended mechanical formability and superior tensile resistance manifested at room temperature [1]. The development of novel advanced TWIP steels requires the evaluation of the effects of the chemical composition design and evaluated accordingly with microstructure evolution and mechanical properties improvement. Subsequently, the development of new high-Mn alloys offers diverse research opportunities [2]. TWIP steels are austenitic single-phase alloys characterized by Mn and $C$ contents in the $15-30 \mathrm{wt} \%$ and $0.3-0.6 \mathrm{wt} \%$ ranges, respectively. Substantial amounts of $\mathrm{Al}$ and $\mathrm{Si}$ are also usually found in these materials [3,4]. In general, TWIP steels can be divided in three category systems based on chemical composition, namely Fe-Mn-C, Fe-Mn-Al-Si and Fe-Mn-Al-C [5,6]. The chemical composition is designed to ensure low stacking fault energy (SFE), generally ranging from 20 to $40 \mathrm{~mJ} / \mathrm{m}^{2}$, and promote mechanical twinning as a deformation mechanism at room temperature [7], generally ranging from 20 to $40 \mathrm{~mJ} / \mathrm{m}^{2}$. Another very important characteristic to highlight is that TWIP steels have a paramagnetic behavior at room temperature. The non-magnetism comes from the evident low permeability, a paramagnetic response of austenite phase that is determined by the face centered cubic (FCC) crystal lattice arrangement when a magnetic field is applied [8]. This behavior is typically observed in stainless steels and austenitic high-Mn steels [9]. In accordance with magnetic measurements carried out in TWIP steels [8], it has been reported that small fractions of $\varepsilon$-martensite cause ferromagnetic behavior in these materials.

Without considering the production route and material resources, the majority of the crude steel melts are cast around the world by using the continuous casting technology. However, it is really a challenge to produce TWIP steels by the continuous casting process because of the problems concerning the high alloy content and production costs [5]. Actually, the limited production of TWIP steels includes those steels fabricated under laboratory conditions (i.e., induction furnace smelting) and industrial scale trials (i.e., twin roll-casting, slabs and strips by conventional continuous casting). In this way, regardless of the production technique, the solidification microstructure (i.e., grain size, shrinkage and segregation) has significant effects on the final steel product performance [10]. After casting, ingots of TWIP steel develop a long oriented columnar dendritic structure as a consequence of non-uniform temperature distribution inside the liquid steel and heat transfer across mold walls. Additionally, due to the cooling process, free inner melt crystallizes, forming equiaxed grains with no preferred orientation. Therefore, the typical ingot solidification structure consists of the chill, columnar and equiaxed zones.

Recently, an effort has been carried out to explain the effect of different compositions over the solidification behavior in TWIP steels. To overcome the castability problem and large-scale free-defects in a Fe-25Mn-Al-3Si ingot TWIP steel, series of complicated casting technologies, such as induction furnace smelting, argon oxygen decarburization (AOD) refining and electroslag remelting, were investigated by Li et al. [5]. Lan et al. [11] studied the microstructure evolution in a Fe-22Mn-0.7C TWIP steel solidified into a nodular cast iron mold, using a high-alumina brick as hot top insulator. Their results indicate that the solidification pattern consists of chill grains, coarse columnar dendrites and equiaxial grains, accompanied by porosity and shrinkage defects. The measured primary dendrite arm spacing (PDAS) and the diameter of the equiaxed grains depend on the heat-transfer capacity of 
the materials forming the mold. Wang et al. [12-14] pointed out that the resulting microstructure in directionally solidified Fe-(25-30\%)Mn-(2.5-3\%)Al-(2.5-3\%)Si TWIP steels exhibits a typical aligned columnar grain structure, and depending on cooling rate, mechanical properties change, in terms of strength and plasticity. Furthermore, they showed that the dendritic arm spacing (DAS) increases, but the morphology becomes simple with decreasing cooling rate. In this sense, Yang et al. [6] evaluated the effect of manganese content, from 0 to $17 \mathrm{wt} \%$, on the solidification pattern developed in a Fe-Mn-Al-C TWIP steel. They have shown a direct relationship between manganese content and columnar grain size in the solidification structure. As manganese content increases, the columnar length and the grain size in steel increase. In the same way, they also observed an increase in the level of austenite stabilization as manganese content increased.

No matter what casting technology is employed to produce high-Mn steels, it is important to note that segregation magnitude in TWIP steels also depends strongly on their solidification conditions. In consequence, their related mechanical behavior affects the as-cast microstructural condition before thermomechanical and thermal material processing. Lan et al. [10] studied the solidification process of Fe-22Mn-0.7C TWIP steel through experimentation and numerical simulation. Most relevant experimental findings agree very well with predicted shrinkage porosity, macrosegregation and grain features evolution during steel solidification. Once solidification takes place, preferential grain orientation is evidenced, which turns up the better conditions for segregation phenomenon to occur. This behavior may result in serious damage because of upward embrittlement susceptibility during hot working.

It is evident then that chemical composition of TWIP steels has a strong influence in their embrittlement susceptibility. During their fabrication, the precipitation of second phases (i.e., carbides, nitrides, carbonitrides, etc.), which have different sizes, morphologies and complexity in nature, takes place even in liquid steel and continues during the solidification process and the final cooling stage in the cast products. Hence, most of the second phases preferentially precipitate at austenite grain boundaries and towards interdendritic regions, weakening them and promoting void nucleation and microcracks propagation [15]. Although hot ductility of TWIP steels has been studied in detail and summarized in some review scientific publications [16,17], few works focused on ensuring those conditions that simulate the hot deformation of the solidified structure as it may be occurring during the strengthening operation in the continuous casting process [18], because related problems are mainly attributed to transverse cracking and surface defects.

As for the effect of boron in enhancing mechanical properties at high working temperatures and influencing phase transformation in different AHSS by increasing their hardenability $[19,20]$, it is very relevant to note that small additions of boron and also other microalloying elements of engineering interest (i.e., vanadium, titanium, niobium, etc.) can improve the hot workability of TWIP steels [21-24]. Kim et al. [25] have shown an evident improvement in the hot workability of Fe-22Mn0.4C TWIP steel when microalloying with titanium and boron, preventing grain boundary embrittlement in the continuous casting process. Boron was added to increase the cohesion strength and titanium for promoting the formation of $\mathrm{Ti}(\mathrm{C}, \mathrm{N})$ instead of $\mathrm{BN}$ precipitates. Thus, fracture of steel after straining changes from brittle to ductile. Moreover, they found that coherent precipitation and segregation of phosphorous on precipitate surfaces are an effective ways of preventing intergranular cracking.

The abovementioned methodology in increasing the effectiveness of boron when combined with titanium in a high-aluminum TWIP steel was first proposed by Kang et al. [26]. These researches obtained values of RA at fracture greater than the minimum $(>40 \%)$ required to avoid transverse cracking. However, in the case of boron addition, ranging between 0.28 and $0.01 \mathrm{wt} \%$, in a medium manganese metastable austenitic steel, tensile testing at room temperature, Li et al. [27] have shown that formed $\mathrm{M}_{2} \mathrm{~B}$-type boride in steel contributes to mechanical resistance but reduces total elongation due fracture mechanism caused by brittle hard boride phase as void formation is encouraged. These findings also highlight a latent harmful effect of boron compounds that must be taken in account during processing of high-Mn austenitic steels at room temperature. Moreover, as the boron 
content increases, boride particle size and population may increase, and the hot ductility of steels gradually becomes worse [28]. Inclusively, the warm deformation process of a steel presenting transformation-induced plasticity (TRIP)/TWIP effects leads to a good balance between high yield strength, good total elongation and high work hardening rate due to the coexistence of deformation twins and $\varepsilon$-martensite [29].

It appears then that a suitable solidification process aided by an inoculation effect produced by microalloying results in an overall refining of the solidification structure and the austenitic grain size in TWIP steels [30]. Hence, under the abovementioned effects of both solidification structure and the micro-addition of elements that affect the microstructural and mechanical behavior of high-Mn austenitic twinning-induced plasticity (TWIP) steels, this research work studies the influence of boron micro-additions (180 and $470 \mathrm{ppm}$ ) on the development of the dendritic microstructure, the magnetic properties and the hot deformation behavior of an advanced as-cast low-carbon highly alloyed TWIP steel.

\section{Materials and Methods}

TWIP steels, identified as TW-B0 (TWIP steel of reference), TW-B1 (TWIP steel containing $180 \mathrm{ppm}$ of boron) and TW-B2 (TWIP steel containing $470 \mathrm{ppm}$ of boron), with a base composition containing Fe-Mn-C-Al-Si-Cr-Ni-Mo-Cu-Ti were fabricated by induction melting in an open-air furnace, using common commercial raw materials (e.g., mild steel, etc.) and ferroalloys. Boron micro-addition was carried out in a single preheated ladle, prior to casting into metallic molds. Carbon and sulfur elemental analysis was performed in a model CS-200 LECO combustion spectrometer (LECO Instruments Ltd., Stockport, UK). In parallel, a Spectro-M11—spark optical spectrometer (Spectro Scientific by AMETEK Inc., Mahwah, NJ, USA) was used for determining the rest of alloyed and microalloyed elements in the steel, except for manganese. At this elapsed time among employed chemical analysis methods, it was decided to probe the accuracy of the portable Thermo Scientific ${ }^{\mathrm{TM}}$ Niton ${ }^{\text {TM }}$ XRF XL5 Analyzer (Thermo Fisher Scientific Inc., Waltham, MA, USA) for measuring manganese content in TWIP steel. This analytical equipment was provided by PetroServicios Company in Mexico [31]. For this purpose, a standard pattern was employed, and the measured manganese content value was in accordance with the initial calculated mass balance for the heat. In this manner, Table 1 summarizes the obtained chemical composition of experimental TWIP steels used in the present work. To estimate precipitation behavior of second phases and the value of the SFE in each TWIP steel, calculation under equilibrium conditions was performed by using JMatPro software (Java-based Materials Properties, 9.0 version, Sente Software Ltd., Guildford, UK), employing the general steel database by collecting data every $10^{\circ} \mathrm{C}$ from liquid state at $1600^{\circ} \mathrm{C}$ to room temperature.

Table 1. Chemical composition of studied low-carbon highly alloyed twinning-induced plasticity (TWIP) steels (in wt\%).

\begin{tabular}{cccccccccccccc}
\hline TWIP Steel & Mn & C & Al & Si & Cr & Ni & Mo & Cu & Ti & B & S & N & Fe \\
\hline TW-B0 & 27.36 & 0.09 & 3.0 & 1.92 & 1.73 & 0.85 & 0.29 & 0.2 & 0.03 & - & 0.02 & 0.012 & Bal. \\
TW-B1 & 27.36 & 0.09 & 3.0 & 1.92 & 1.73 & 0.85 & 0.29 & 0.2 & 0.03 & 0.018 & 0.02 & 0.012 & Bal. \\
TW-B2 & 27.36 & 0.09 & 3.0 & 1.92 & 1.73 & 0.85 & 0.29 & 0.2 & 0.03 & 0.047 & 0.02 & 0.012 & Bal. \\
\hline
\end{tabular}

On the other hand, from TW-B0, TW-B1 and TW-B2 cast ingots, there were cut samples for metallographic inspection. Hence, samples were obtained from the transversal section at the bottom of each ingot. Thus, these samples represent the quarter part of the initial sectioned steel samples (see Figure 1). Then, samples were prepared mechanically by conventional SiC grinding papers, followed by sequentially $6,3,1$ and $0.1 \mu \mathrm{m}$ mechanical polishing, using monocrystalline diamond paste. After metallographic preparation, special care was put on samples' surface cleanliness. Then, dendritic microstructural features and austenitic grain boundaries of the as-cast structure of TWIP steels were revealed by employing a stepped chemical etching immersion procedure: firstly, employing Nital 
(10\%) reactant solution for $40 \mathrm{~s}$, and then followed by Glyceregia (10\%) reactant solution composed by $\mathrm{HNO}_{3}+\mathrm{HCl}+\mathrm{C}_{3} \mathrm{H}_{8} \mathrm{O}_{3}$, during $2 \mathrm{~min}$, at room temperature. Thus, global microstructure was analyzed by using an Olympus PMG 3 optical microscope (Olympus Corporation of the Americas (OCA), Center Valley, PA, USA). Besides this, a series of low-magnification micrographs were taken, to track solidification patterns (i.e., columnar and equiaxed zones), as illustrated in Figure 1a. In this manner, after building a collage-type high-image-quality surface record, it was possible to measure primary and secondary dendrite arm length and austenitic grain size through image analysis, using SigmaScan Pro V5.0 software (Systat Software Inc., San Jose, CA, USA). Finally, as an effort to know the effect of chemical composition on mechanical properties of the as-cast structure microhardness $\left(\mathrm{HV}_{0.5}\right)$, measurements tests were carried out by using a Novotest TC-MCV-1A microhardness tester (NOVOTEST Ltd., Novomoskovsk, Ukraine). The separation among indentations was a half millimeter, as shown in Figure 1b.

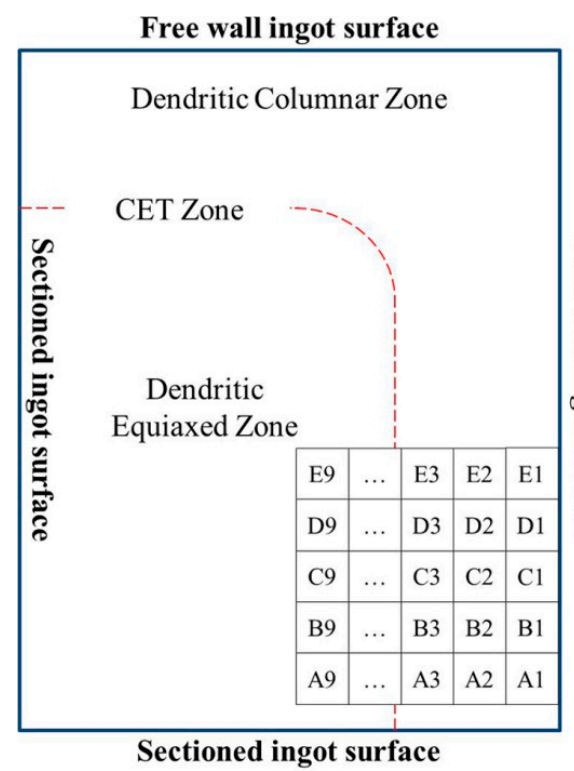

(a)

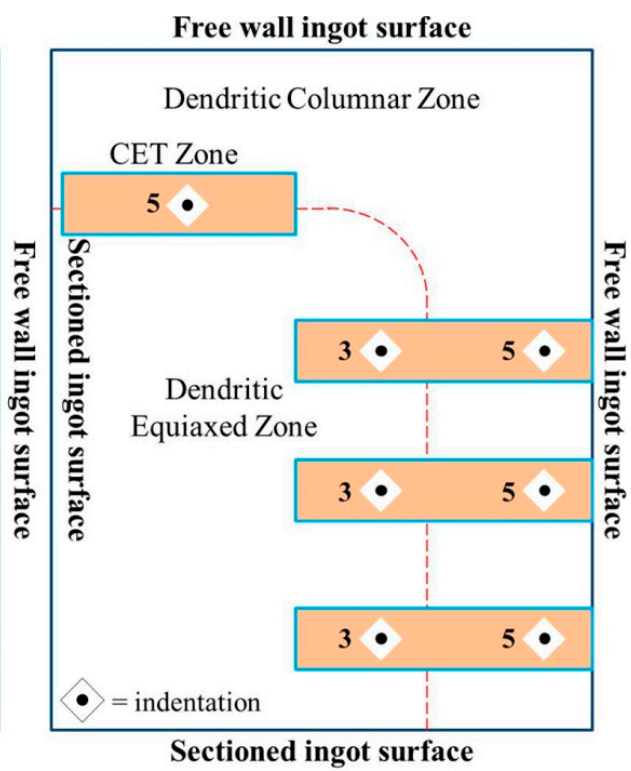

(b)

Figure 1. A quarter of TWIP steel ingot sample: (a) image arrangement procedure for tracking solidification zones and microstructure and (b) microhardness testing methodology.

Detailed microstructural analysis was carried out by electron scanning microscopy (SEM), as an attempt to determine segregation patterns of alloying and microalloying elements established during solidification process. To get the better conditions for revealing microstructural features on samples surface, they were again etched by using Nital (10\%) solution, during $10 \mathrm{~s}$, at a constant temperature of $60{ }^{\circ} \mathrm{C}$, on the earlier abovementioned stepped etching procedure. After this, ultrasonic cleaning was performed once again. In this way, elemental microanalyses, using energy-dispersive X-ray spectrometry (EDX), were performed with a JEOL JSC-6000 Plus Neoscope instrument (JEOL Ltd., Tokyo, Japan), operated at accelerating voltages of 10, 15 or $20 \mathrm{keV}$.

An important experiment carried out in these studied TWIP steels consisted of determining their magnetic properties in the as-cast and as-cold-rolled conditions. This study was executed with the aim of comparing the simultaneous effect of thermomechanical treatment and mechanical work of steel microstructure over magnetic properties, when compared with the as-cast condition. Thus, from each TW-B0, TW-B1 and TW-B2 ingot, we cut samples of $5 \mathrm{~cm} \times 2.5 \mathrm{~cm} \times 2.5 \mathrm{~cm}$ in dimension and homogenized them at $1100{ }^{\circ} \mathrm{C}$, during $3 \mathrm{~h}$. This heat treatment destroyed the segregation patterns produced by solidification. These samples were then sequentially hot-rolled from $1100^{\circ} \mathrm{C}$, to reduce the cross-section by about $80 \%$. The finishing rolling temperature was approximately $800{ }^{\circ} \mathrm{C}$. At this stage, the hot-rolled samples were fast cooled into oil. Finally, the cross-section of the as-hot-rolled samples 
was reduced at room temperature, by applying 30 passes, until achieving a final thickness of $1 \mathrm{~mm}$, a condition in which mechanical twins are formed in the inner austenitic grains. Hot- and cold-rolling operations were carried out in a $25 \mathrm{hp}$ reversible Fenn Amca-5Mill rolling mill (International Rolling Mills Inc., Pawtucket, RI, USA).

From both as-cast and as-cold-rolled conditions, thin plates of $7 \mathrm{~g}$ in weight served as samples for magnetism measurements. For each sample, the magnetic hysteresis loop was obtained by using a MicroSense EV7 vibrating sample magnetometer (VSM) (MicroSense, LLC, Lowell, MA, USA) at room temperature $\left(\approx 20{ }^{\circ} \mathrm{C}\right)$ and a maximum magnetic field of $(+/-) 18$ kilo oersted $(\mathrm{kOe})$. To establish the type of crystal structure present in the samples during determination of the hysteresis loops, X-ray diffraction analyzes were performed in the $2 \theta$ interval from 40 to $130^{\circ}$, using a K $\alpha$ Co radiation $(45 \mathrm{kV}-18$ $\mathrm{mA}$ ), with a scanning step of $0.013^{\circ}$ and a counting time of $13.7 \mathrm{~s}$ in a Siemens D5000 diffractometer (Siemens AG, Munich, Germany).

As these experimental TWIP steels are highly alloyed and also contain micro-additions of boron, it was necessary to investigate their hot ductility behavior conserving the as-cast structure. This is important because of the large number of precipitated particles that may cause embrittlement when the steel is subject to hot plastic deformation. Therefore, uniaxial hot-tensile tests were performed, to evaluate their high-temperature ductility. For this purpose, sets of cylindrical tensile samples were obtained from solidified TWIP steel ingots, ensuring that they were taken off from dendritic columnar zone, near the free wall ingot surface, due to the importance in simulating the strengthening operation during the continuous casting process. As the strengthening operation was carried out between 1100 and $700{ }^{\circ} \mathrm{C}$ during the continuous withdrawal of the strand from the mold, hot ductility was measured at 700, 900 and $1100{ }^{\circ} \mathrm{C}$, using a constant strain rate of $0.001 \mathrm{~s}^{-1}$. Thus, isothermal uniaxial hot-tensile testing was performed by employing a servo hydraulic universal testing machine (MTS System Corporation, Eden Prairie, MN, USA) equipped with a radiant cylindrical furnace, which was instrumented with K-type probe thermocouple sensors. The radiant cylindrical furnace was coupled to a temperature control module in which testing thermal cycles were scheduled for each tensile test. The first step consisted of heating samples to $1100{ }^{\circ} \mathrm{C}$, at a heating rate of $75^{\circ} \mathrm{C} / \mathrm{min}$, and soaked during $15 \mathrm{~min}$. Then, according to the testing temperature, the experimental steel samples were rapidly cooled to the target temperature and then maintained for $5 \mathrm{~min}$, before straining, and finally tensile tested until fracture. To avoid material oxidation during hot-tensile testing, an inert atmosphere was produced by using argon gas within the chamber of the cylindrical furnace. A flow of argon gas was used as quenching media to cool down the strained samples after fracture. Figure 2 shows cylindrical tensile sample dimensions and the employed thermal cycle for uniaxial hot-tensile testing. Lastly, surface SEM images of fractured samples were obtained and digitally treated to determine the percentage of reduction in area at fracture (\% of RA), which was assumed as the hot ductility.

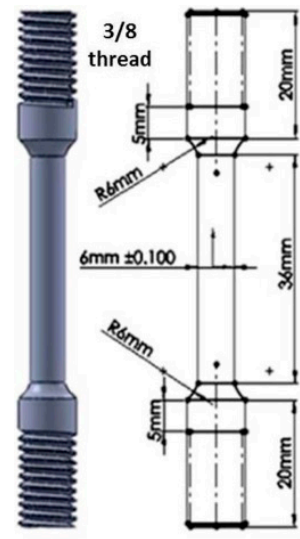

(a)

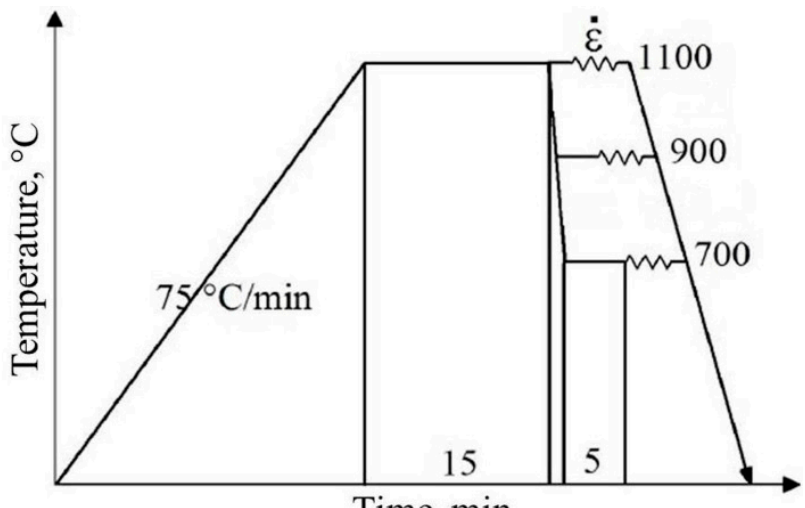

Time, $\min$

(b)

Figure 2. Hot tensile testing: (a) cylindrical sample and (b) applied thermal cycle. 


\section{Results and Discussion}

\subsection{JMatPro Phases Prediction}

Figure 3 shows the theoretical calculations of phases and other equilibrium compounds formed when boron is added in a small proportion to TWIP steel. It is observed that the solidification start temperature for the three steels is $1375.83^{\circ} \mathrm{C}$. However, the solidification ending temperatures decrease as the boron content increases in the steel. In the case of TW-B0, this temperature corresponds to $1312.78{ }^{\circ} \mathrm{C}$ (see Figure 3a); meanwhile, for TW-B1, it is $1280{ }^{\circ} \mathrm{C}$ (see Figure $3 \mathrm{~b}$ ), and for the case of TW-B2, it is $1190{ }^{\circ} \mathrm{C}$ (see Figure 3c), respectively. As can be seen, boron micro-addition extends the biphasic liquid-solid region and, as a result, promotes major segregation during solidification, due the longer time to reach alloy crystallization. On the other hand, the results of the calculations show that the AlN compound forms in the liquid state in the three steels and practically remains stable until room temperature, in an amount of $0.045 \mathrm{wt} \%$. It has been suggested [32] that the rate at which this compound precipitates is controlled by a chemical driving force and affects the solidification structure by increasing the length of the columnar zone, which in turn promotes embrittlement. In the same contextualization, $\mathrm{MnS}$ compound precipitates just as the solidification process starts, showing a stable behavior until $0.070 \mathrm{wt} \%$ and at $510{ }^{\circ} \mathrm{C}$ in TW-B0, $500{ }^{\circ} \mathrm{C}$ in TW-B1 and $490{ }^{\circ} \mathrm{C}$ in TW-B2, respectively. At these mentioned temperatures, some $S$ contained in the MnS decomposes into $\mathrm{Ti}_{4} \mathrm{C}_{2} \mathrm{~S}_{2}$ compound. In fact, the precipitation behavior of $\mathrm{AlN}, \mathrm{MnS}$ and $\mathrm{Ti}_{4} \mathrm{C}_{2} \mathrm{~S}_{2}$ compounds is very similar in TW-B0 and TW-B1. Precipitation of these compounds in TW-B2 exhibits a different behavior. Besides that, $\mathrm{Cu}$-rich phase-containing elements such as $\mathrm{Ni}, \mathrm{Al}, \mathrm{Mn}, \mathrm{Ti}$ and $\mathrm{S}$ form at temperatures as low as $450{ }^{\circ} \mathrm{C}$ and get a higher amount concentration around $0.21 \mathrm{wt} \%$, at room temperature, in the three steels. Takaki et al. [33] have claimed that $\mathrm{Cu}$ precipitation in steel has a strong effect in encouraging a better balance between strength and ductility relationship due to the diverse chemical nature of $\mathrm{Cu}$ precipitates, when compared with carbides and nitrides. Moreover, an increase in strength can be achieved by grain refinement and aging heat treatments. However, $\mathrm{Cu}$ phase morphology and size can generate a certain susceptibility to hydrogen embrittlement [34]. Additionally, the precipitation of more common $\mathrm{M}(\mathrm{C}, \mathrm{N}), \mathrm{M}_{23} \mathrm{C}_{6}$ and $\mathrm{M}_{6} \mathrm{C}$ compounds is observed in the three TWIP steels.

It is evident in Figure 3 that precipitation of boron compounds behaves quite differently in both boron micraolloyed TWIP steels. In the case of TW-B1, boron $\mathrm{MB}_{2} \mathrm{C}_{32}$ and $\mathrm{M}_{3} \mathrm{~B}_{2}$ compounds are formed at higher temperatures. The $\mathrm{MB}_{2} \mathrm{C}_{32}$ compound only exists at a higher temperature. It precipitates in the mushy zone close to the solidus line and increases its content to $0.047 \mathrm{wt} \%$, which remains stable from 1279.28 to $861.93^{\circ} \mathrm{C}$, and finally gets completely dissolved in the austenitic phase at $801.43{ }^{\circ} \mathrm{C}$. As a result, this precipitate can be very harmful during thermomechanical processing of the steel, because it is present in the critical temperature range, where most of the hot forming processes are carried out, and within them is the strengthening operation in the continuous casting process. In spite of the presence of this harmful compound, the pure $\mathrm{M}_{3} \mathrm{~B}_{2}$ compound starts forming at $1097^{\circ} \mathrm{C}$ and increases its content to $0.22 \mathrm{wt} \%$, as the temperature decreases to $800{ }^{\circ} \mathrm{C}$. After that, $\mathrm{M}_{3} \mathrm{~B}_{2}$ remains stable up to room temperature in $0.23 \mathrm{wt} \%$. It is noteworthy that this boride is present in a wide temperature range, which includes all the typical forming and heat-treatment operations used for steel. In contrast, as the content of boron in TW-B2 increases, three boron compounds are formed, namely $\mathrm{M}_{3} \mathrm{~B}_{2}, \mathrm{Fe}_{2} \mathrm{~B}$ and $\mathrm{Cr}_{2} \mathrm{~B}$, where $\mathrm{M}_{3} \mathrm{~B}_{2}$ compound remains stable at room temperature in about $0.4 \mathrm{wt} \%$ (see Figure $3 \mathrm{~d}$ ), almost double the content exhibited by TW-B1. However, from a higher temperature, $\mathrm{Fe}_{2} \mathrm{~B}$ decomposes and contributes to form $\mathrm{Cr}_{2} \mathrm{~B}$, a compound that remains stable until room temperature in $0.13 \mathrm{wt} \%$. In general terms, the selected chemical composition for both boron-containing TWIP steels has inhibited the formation of the most harmful BN compound [21-23]. However, complex-boron compounds can promote an unwanted effect on TWIP steel corrosion resistance in the as-cast and as-cold-rolled conditions [30]. 


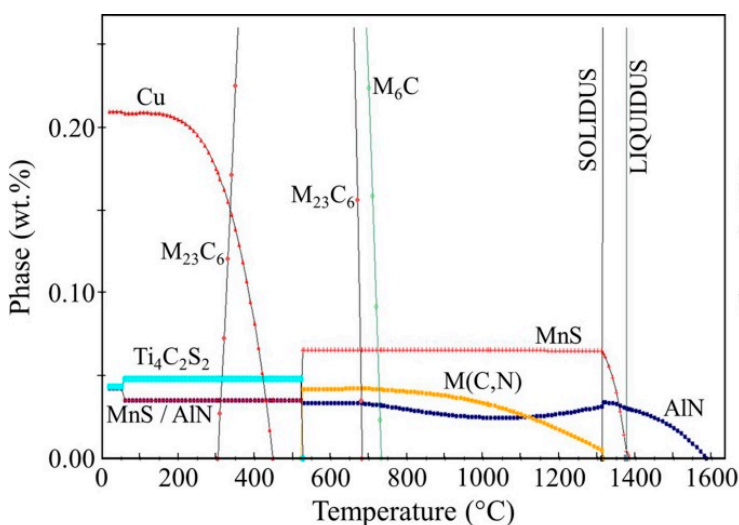

(a)

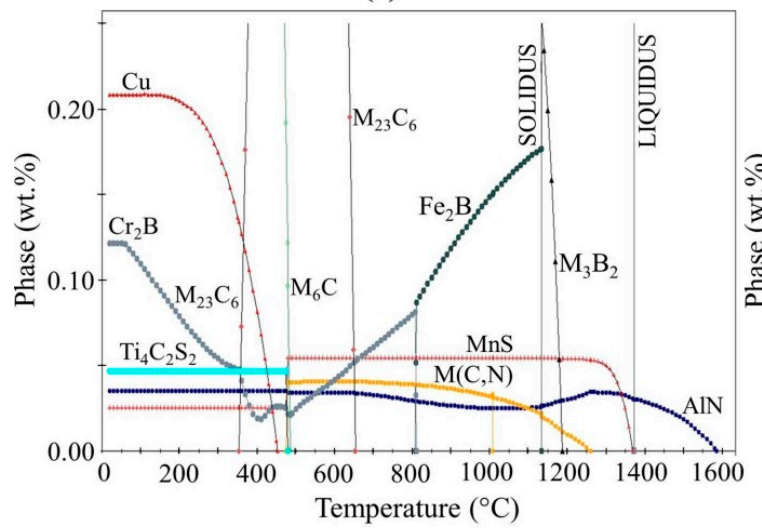

(c)

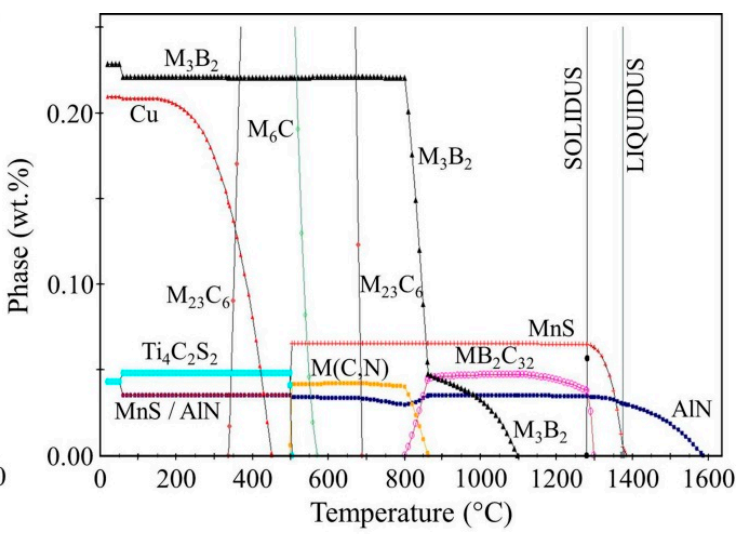

(b)

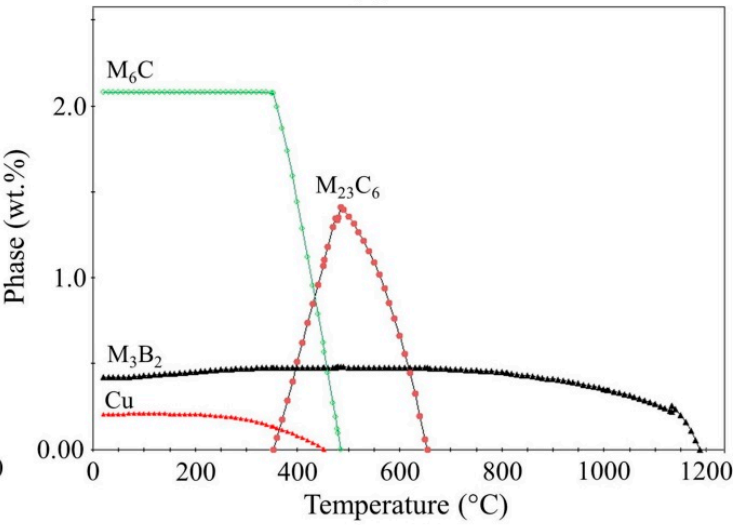

(d)

Figure 3. Amount of predicted phases (wt\%) at equilibrium conditions calculated with JMatPro software in studied TWIP steels: (a) TW-B0, (b) TW-B1 and (c,d) TW-B2.

\subsection{Solidification Structure of Advanced TWIP Steel}

Figure 4 shows the solidification structure of TW-B0, containing the columnar and equiaxed zones. The formed solidification microstructure is different from that typically observed in most cast steel ingots, consisting of well-established dendritic primary/secondary/tertiary/high-order branched morphology [35]. The boundaries of the austenite grains in both columnar and equiaxed zones are delineated by primary dendritic arms. This means that the main dendrite trunks in both columnar and equiaxed zones do not exhibit secondary arms on one side-branch. Fine and elongated secondary dendritic arms can sometimes develop in the other side-branch of the primary dendritic arms, although, in other regions, coarse secondary arms of varying lengths can also be observed. A similar pattern develops in tertiary dendritic arms on secondary dendritic arms. Hence, in this manner, austenitic grains can be easily recognized.

Figure 5 shows optical (Figure $5 \mathrm{a}, \mathrm{c}$ ) and SEM (Figure 5b,d) micrographs illustrating the morphology of the microstructure in the columnar (Figure $5 a, b$ ) and equiaxed (Figure $5 c, d$ ) zones in TW-B0. Primary and secondary dendritic arms are clearly observed. Previously, this type of solidification microstructure has been identified as incoherent dendritic crystallization [30], a type of multilayered (austenite + ferrite) dendritic microstructure. This solidification structure has been observed in other TWIP steels $[13,36]$.

In TW-B0, from the featureless molten metal, and taking into account factors such as the temperature gradient, the solidification rate and the initial solute concentration are how complex dendrite morphology and distribution get established. Due to an undercooled thermodynamics and kinetics in the liquid-to-solid phase transformation front favors the free growth stage condition during the solidification process. This means that the growth of primary dendritic arms is even toward the center of the liquid, competing at the same time with the growth of similar crystals. As this 
happens, there is not enough space for secondary arms to growth, and thus austenitic grain boundaries are easily observed in the solidification microstructure. However, the 3D morphology of the entire dendrite becomes difficult to imagine. Regarding the rest of the solidification microstructure inside each austenitic grain, a remaining crystallization is observed due to a larger mushy zone. This type of dendritic crystal is formed as a consequence of the primary dendrite tips that are split for branching and form concave pits and in which secondary dendrites tend to branch obliquely, so their geometry is no longer orthogonal (likewise in their parent-primary arms) [37].

The solidification microstructures of the boron-microalloyed TWIP steels (TW-B1 and TW-B2) are shown in Figures 6 and 7, respectively. As can be seen, a typical primary and secondary branched dendritic morphology is observed containing few ramified dendrites per columnar or equiaxed grain. As temperature decreases toward the mold walls, the non-uniform temperature distribution in melt causes long columnar dendritic crystals, growing parallel to the thermal gradient. Thus, as cooling proceeds during solidification, free equiaxed dendritic grains growth without preferred orientation in the residual free liquid as the temperature falls below the melting point. It is important to take into account that the TWIP steels investigated are highly alloyed and, as a result, larger levels of interdendritic segregation can be expected. This effect also helps contrasting the dendritic microstructure. In general, compared with the steel without boron content (TW-B0), the solidification structure of boron microalloyed TW-B1 and TW-B2 steels exhibit a significant refinement of the dendritic microstructure (primary and secondary dendritic arms) and austenitic grain size.

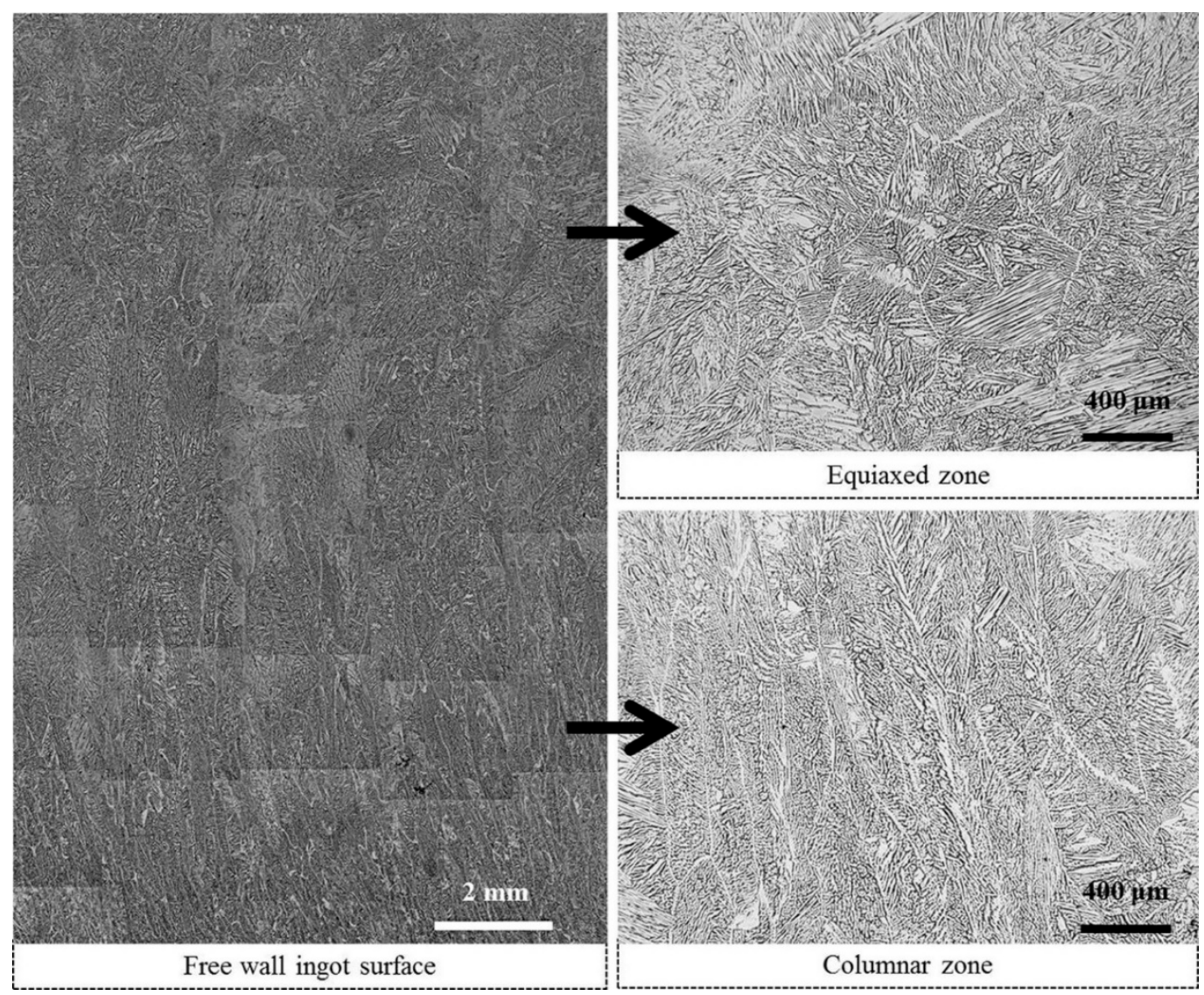

Figure 4. Solidification microstructure of TW-B0. 


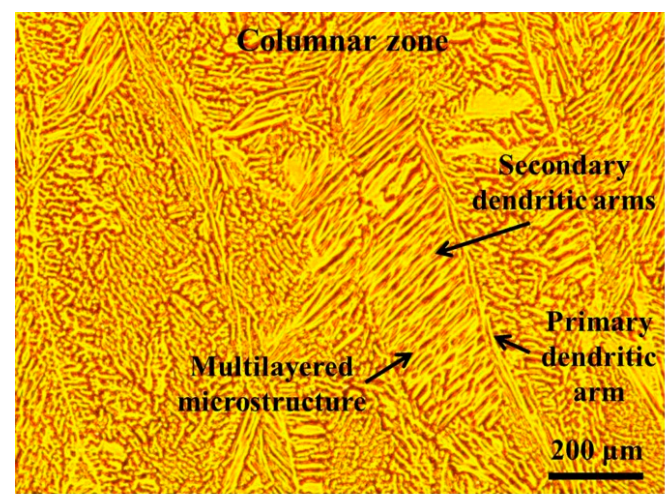

(a)

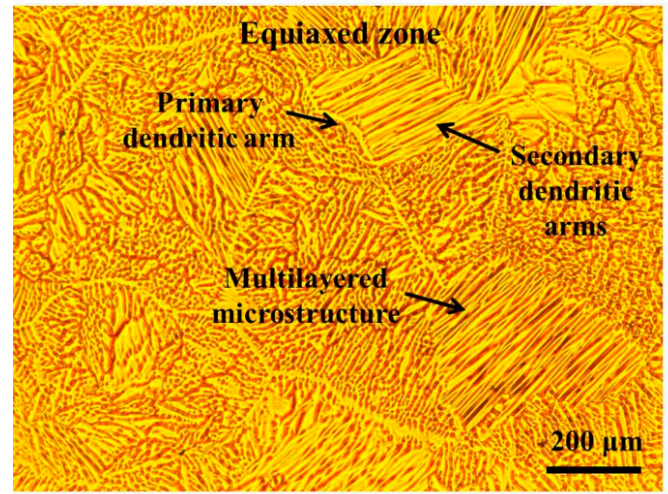

(c)

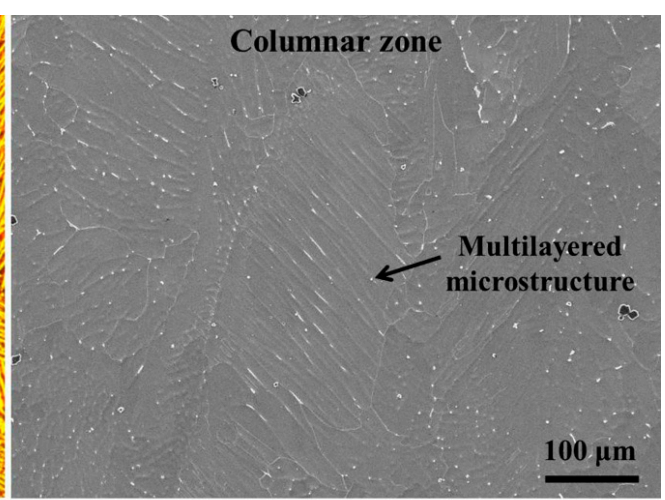

(b)

Equiaxed zone

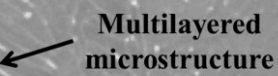

$50 \mu \mathrm{m}$

(d)

Figure 5. Primary and secondary dendritic microstructure in TW-B0: $(\mathbf{a}, \mathbf{c})$ optical micrographs and (b,d) SEM micrographs.

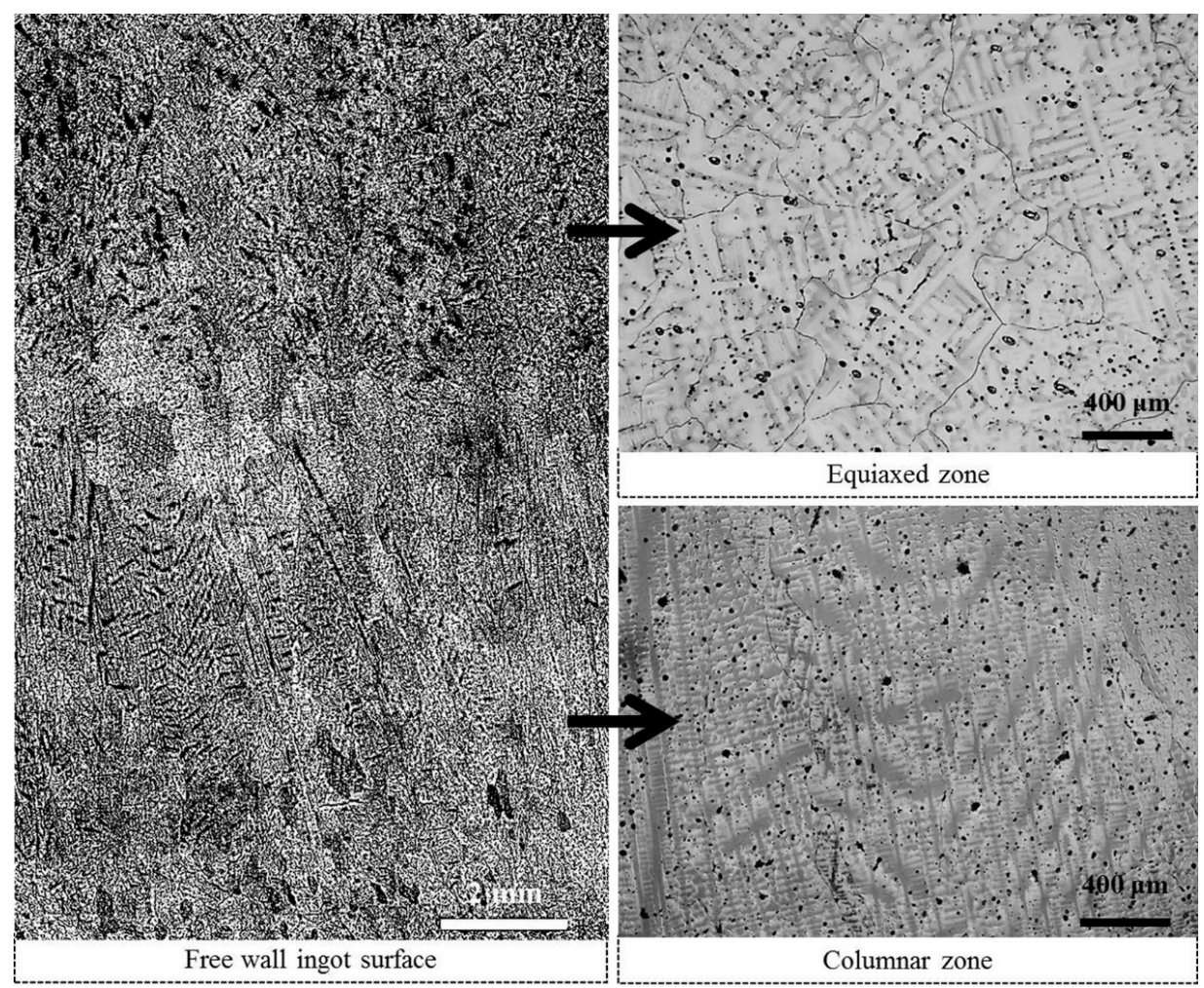

Figure 6. Solidification microstructure of TW-B1. 


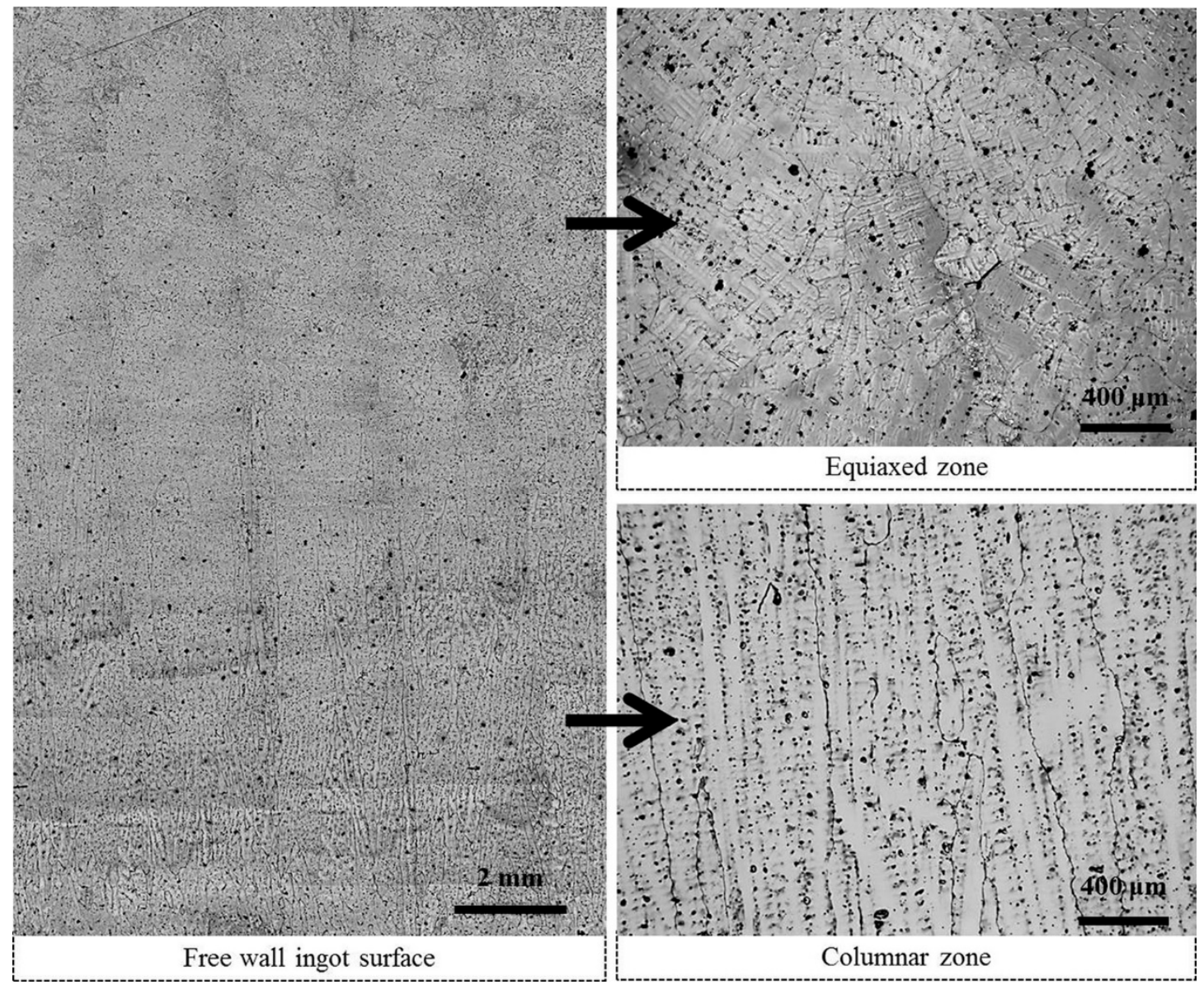

Figure 7. Solidification microstructure of TW-B2.

In addition, it seems that, as boron content increases in steel (comparing Figures 6 and 7), the dendrites inside each austenitic grain become finer. It is important to note that dendritic growth represents a peculiar behavior, where dendrites (including primary, secondary and even tertiary arms) grow in specific crystallographic directions determined by the physic-chemical properties of the material. In the present steels, the growing crystalline phase is austenite, and the growing directions of the dendritic arms belong to the $<100>$ family. The observed coarsening of secondary dendritic arms in both boron microalloyed TWIP steels is an important feature of dendrite evolution. As dendrite tip spreads through the melt, small perturbations grow in the main trunk against side-branches, and, after further growth in a melt that approaches phase equilibrium, coarsening takes place, reducing the number of secondary and higher-order arms, leading to an increase in their size [38]. Finally, the resulting macrostructure and microstructure exhibits significant solute segregation. This results in the non-uniform chemical composition that affects the quality of the TWIP steel ingots quality. This fact falls into an inherent situation among steel community, since, historically, the occurrence of metallurgical phenomena that adversely affect product quality in foundries, namely poor surface quality, segregation, volumetric defects and, therefore, low metallic yield, is very important. Furthermore, this is a case of industrial experience, since, through the years, the fact of fabricating special steel grades means that there are few steelmakers around the world that can ensure their production.

SEM elemental analysis, using line scans through the as-cast microstructure, was performed at the secondary dendritic arm regions. Figure 8 presents the solute profiles for the three steels. It can be observed that the concentration of $\mathrm{Fe}$ and $\mathrm{Mn}$ elements decrease in the interdendritic regions. Contrarily, $\mathrm{Al}, \mathrm{Si}$ and $\mathrm{C}$ elements have increased their concentration in the same interdendritic regions. It is noteworthy that variation of $\mathrm{Si}$ content is more pronounced than that observed for $\mathrm{Al}$, even though Si content in the steel is lower. This chemical inhomogeneity can lead to embrittlement due to the 
formation of second-phase particles, as indicated in Figure 3. Comparing boron microalloyed TWIP steels, we see boron concentration variation can also be slightly perceived, and a marked influence at the interdendritic regions is identified, being this solute-enrichment more evident at grain boundaries.

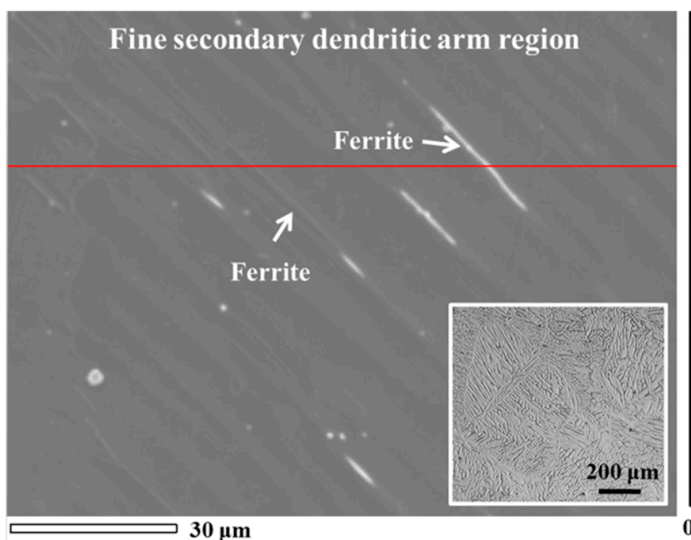

(a)

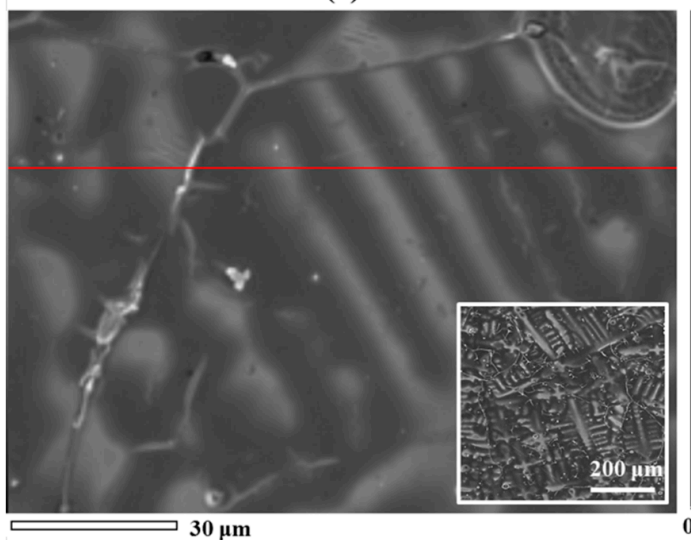

(c)

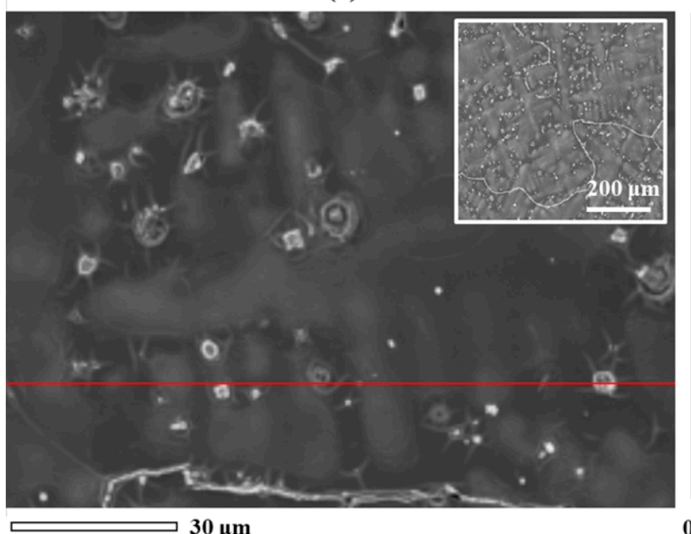

(e)

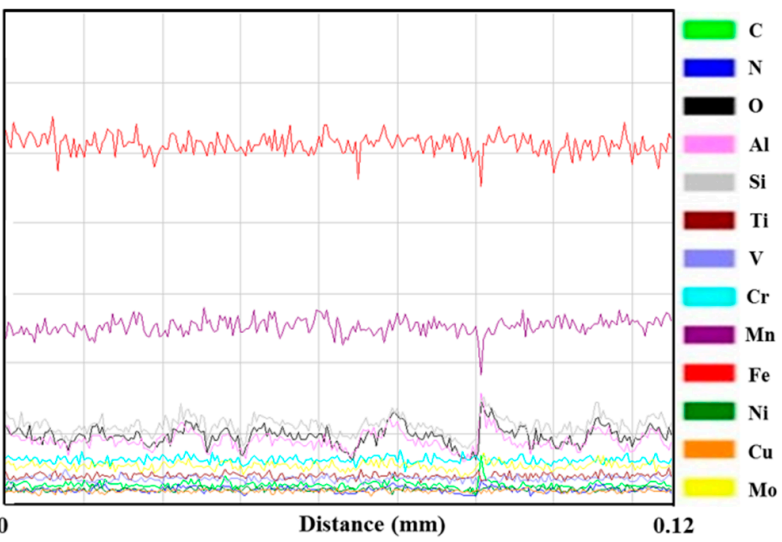

(b)

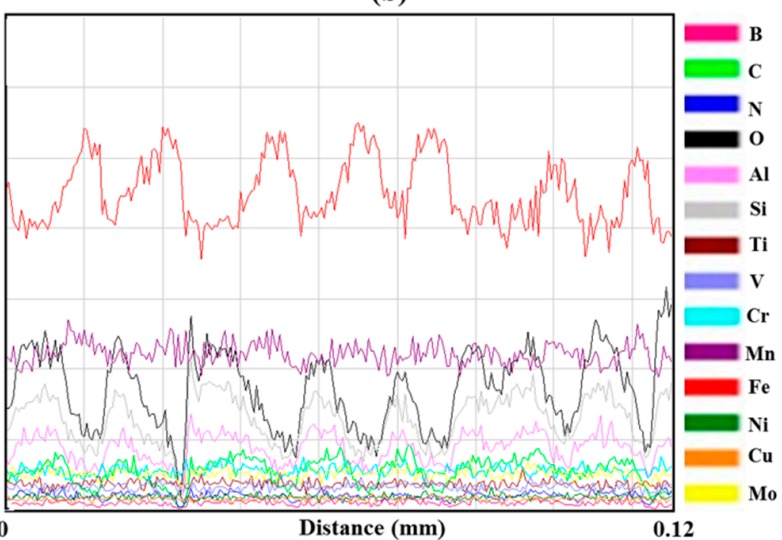

(d)

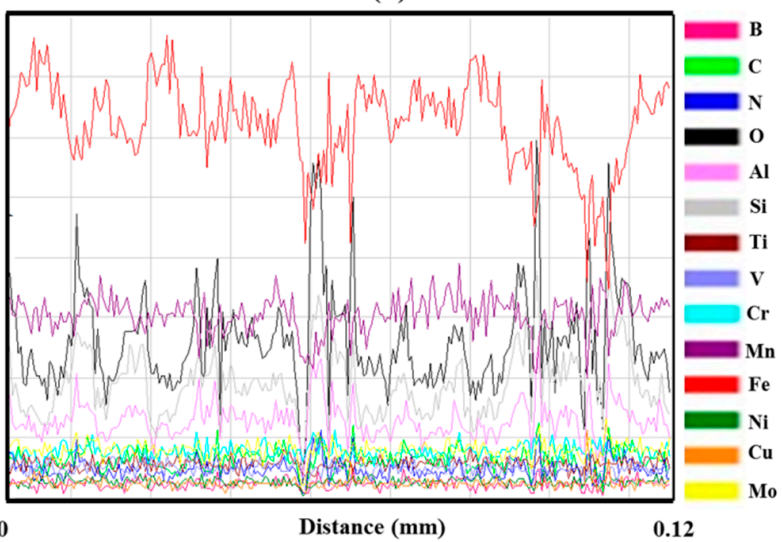

(f)

Figure 8. Solute segregation profile along solidification structure in studied low-carbon highly alloyed TWIP steel: (a,b) Microstructure and SEM-EDX analysis by line scanning in TW-B0; (c,d) microstructure and line scan SEM-EDX analysis in TW-B1; and (e,f) microstructure and line scan SEM-EDX analysis in TW-B2.

However, boron segregation is more evident in TW-B1 than in TW-B2, although TW-B1 has lower boron content. Furthermore, TW-B2 exhibits a larger amount of boron compounds. Even some population of the total precipitated particles can be compared in micrographs of Figure $8 \mathrm{c}$, between each alloy. In addition, segregation of interstitial boron element can have a significant importance over constitutional undercooling and modify in this way the dendritic morphology due some boron atoms 
can act as nuclei sites for crystallization and the rest of boron atoms can precipitate commonly at grain boundaries, behavior promoted by a solute drag mechanism [24,39]. It is worth noting that boron may be considered one of the best microalloying elements when considering its chemical effectiveness in terms of costs. Notably, solid solution effectiveness of boron as a microalloying element can be enhanced if some titanium is added to melt. In such a way, titanium exhibits a larger tendency to form stable compounds with dissolved nitrogen, such as $\operatorname{TiN}$ or $\operatorname{Ti}(\mathrm{C}, \mathrm{N})$, instead of $\mathrm{BN}$, considered a very harmful compound. Thus, soluble boron in deformed austenite occupies vacancy sites throughout non-equilibrium segregation and enhances grain boundary cohesion.

Figure 9 shows the morphology of some boron-containing particles (i.e., carbide and boron carbide nitride) precipitated at grain boundaries for both TW-B1 and TW-B2 steels. The chemical composition of these particles matches very well with the chemical nature predicted by JMatPro calculations in Figure 3 and their morphologies are in agreement with those ones reported by Mejía et al. [21]. The fact that these precipitated particles are located at grain boundaries increases to a greater extent the brittleness of the steel. Furthermore, localized concentration of solute elements can generate specific energetic conditions for activating phase transformation reactions. So, this local activity represents one of the promoters in changing the deformation mode of these advanced high-Mn austenitic TWIP steels.

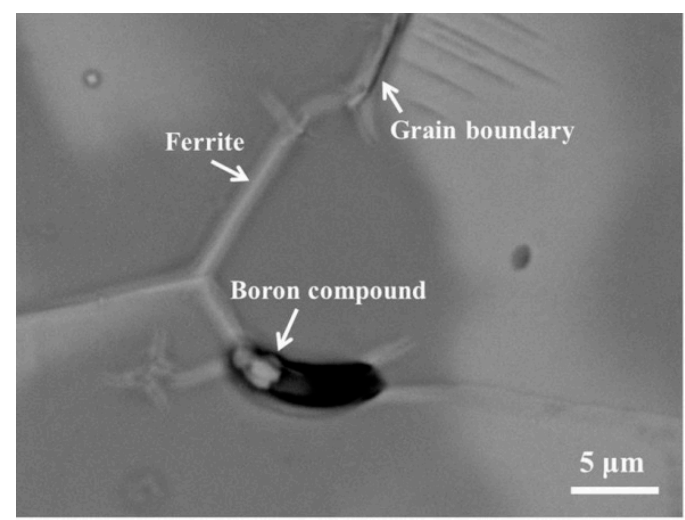

(a)

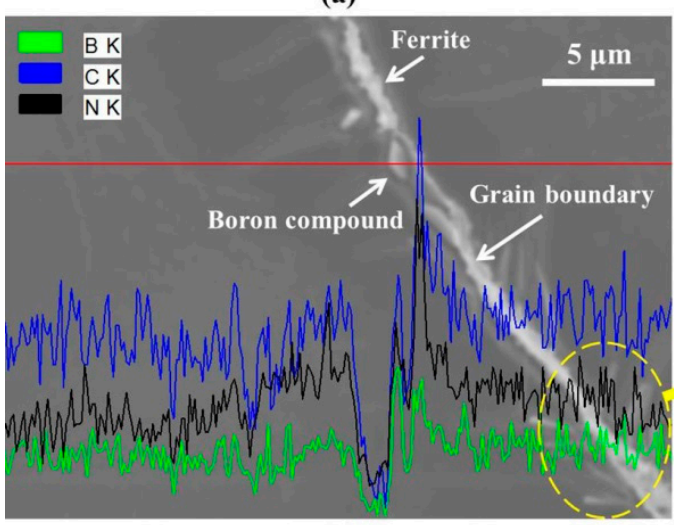

(c)

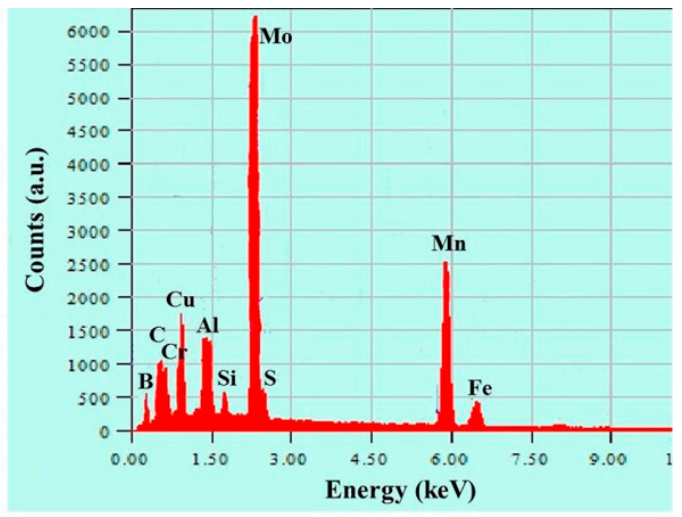

(b)

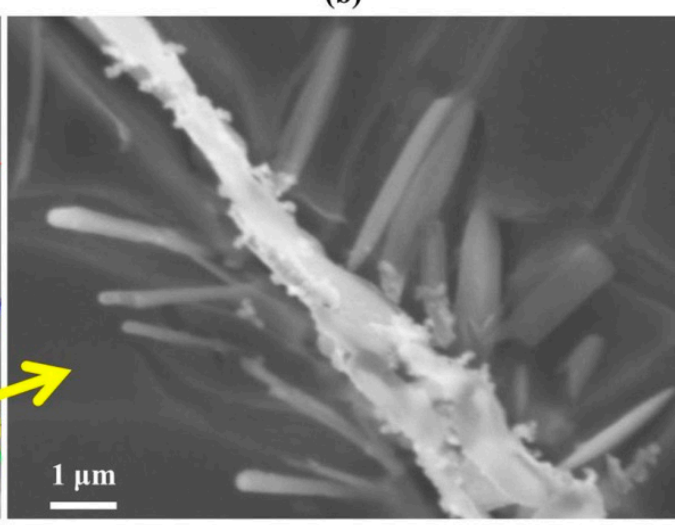

(d)

Figure 9. Boron compounds identified in the dendritic microstructure and located at grain boundaries: (a) SEM micrograph of TW-B1, (b) elemental SEM-EDX analysis of particle in TW-B1, (c) SEM micrograph of TW-B2 showing an over layer line scan, and (d) grain boundary SEM micrograph magnification in TW-B2.

Table 2 summarizes the results of the measurements carried out along columnar and equiaxed zones, comparing the length of primary and secondary dendritic arms, as well as the austenitic grain size in the three studied TWIP steels. In general terms, a refining effect can be confirmed in the solidification structure, due to the boron micro-addition, as a function of its increase in the steel. Nonetheless, it is evident that secondary dendritic arms in the equiaxed zone have longer lengths than 
in the columnar regions. The equiaxed zone refers more to uniform morphology of dendrites in the space after steel has reached its solidification, in which austenitic grain size does in the same way. Besides that, a relationship seems to exist between austenitic grain size and boron content. In one hand, the steel of reference (TW-B0) has an austenitic grain size of $770.09 \mu \mathrm{m}$ in the columnar zone and 531.86 $\mu \mathrm{m}$ in the equiaxed zone. These values of grain size are the bigger ones than in boron-containing steels, as it happens in the same manner on dendrite arm measurements. On the other hand, in the case of the columnar zone, when TWIP steel is microalloyed with $180 \mathrm{ppm}$ of boron, austenitic grain size has a value of $656.24 \mu \mathrm{m}$ and when it is microalloyed with $470 \mathrm{ppm}$ of boron, austenitic grain size value is $577.20 \mu \mathrm{m}$. In the equiaxed zone, when TWIP steel is microalloyed with $180 \mathrm{ppm}$ of boron, austenitic grain size reaches $423.02 \mu \mathrm{m}$, and when it is microalloyed with $470 \mathrm{ppm}$ of boron, the austenitic grain size has a value of $344.87 \mu \mathrm{m}$. There is an approximately $15 \%$ of austenitic grain refinement in the columnar zone and about $20 \%$ of refinement in the equiaxed zone, consecutively in each TWIP steel.

Table 2. Average values of measured primary and secondary dendritic arm length and austenitic grain size.

\begin{tabular}{ccccccc}
\hline TWIP & \multicolumn{2}{c}{ Primary Dendritic Arm $(\mu \mathrm{m})$} & \multicolumn{2}{c}{ Secondary Dendritic Arm $(\mu \mathrm{m})$} & \multicolumn{2}{c}{ Austenitic Grain Size $(\mu \mathrm{m})$} \\
\cline { 2 - 6 } Steel & Columnar & Equiaxed & Columnar & Equiaxed & Columnar & Equiaxed \\
\hline TW-B0 & 766.59 & 518.08 & 338.99 & 365.85 & 770.09 & 531.86 \\
TW-B1 & 705.71 & 455.67 & 180.83 & 192.80 & 656.24 & 423.02 \\
TW-B2 & 601.25 & 304.37 & 99.81 & 118.10 & 577.20 & 344.87 \\
\hline
\end{tabular}

In consequence, since this refinement tendency is also observed for the dendritic arms, a positive effect of boron is shown for refining the overall solidification structure. Moreover, the effect of microalloying elements during the solidification of TWIP steels is to enlarge the constitutional undercooling regime due to the rejection of solute elements. Accordingly, coarse and fine particles are formed in melt, which in turn act as nucleation sites for forming equiaxed grains. Therefore, the high thermal gradients reached in the liquid-solid interface produce a strong natural convective motion in the molten metal, fragmenting dendrite branches and achieving greater structure refinement. Additionally, the data obtained in this work indicate that the columnar-to-equiaxed transition (CET) zone is bigger in TW-B0, having a length in about $10 \mathrm{~mm}$, medium length in TW-B1 in approximately $7 \mathrm{~mm}$ and smaller in TW-B2 in around $6 \mathrm{~mm}$. Thus, boron micro-addition also reduces the CET.

This solidification structure refining is attributed to the occurrence of extended crystallization in the residual liquid wherein too many equiaxed crystals can form. Hence, equiaxed grains are formed thanks to an inoculation mechanism during heterogeneous solidification, in which solid particles or groups of atoms serve as nucleation sites if a coherency in crystallinity between solid particles and solid phase of the steel has the most similar atom arrangement. In the current case of TWIP steels, this crystalline coherency is due to the FCC phase. Moreover, the size of solid particles must be as fine as possible for achieving the critical radius and the wettability angle to reach crystallization.

\subsection{Magnetic Behavior of Advanced TWIP Steel}

High-Mn TWIP steels are characterized by non-magnetic interactions when they are exposed to an external magnetic field. Taking into account the microstructure, the magnetism behavior of studied TWIP steels in the as-cast and as-rolled conditions is shown in Figure 10a,b. In the case of TWIP steels with solidification structure, a ferromagnetic behavior is observed as boron content increases in the steel, beginning from a weak magnetic manifestation for TW-B0, increasing a little in TW-B1 and being more evident in TW-B2. As a matter of fact, it can be said that TW-B2 has a well-established ferromagnetic behavior, as indicated by the hysteresis loop in Figure 10a. As TWIP steels are non-magnetic materials, moving them in the factory is a complex operation. In technical terms, the observed magnetic behavior in TW-B2 can be positively used to move already cutoff cast strands (e.g., slabs or billets) to other sites in the steelmaking plant (e.g., storage warehouse for the reheating operation) employing the 
electromagnetic overhead traveling crane (electromagnetic chuck). Consequently, greater security might be obtained transporting blooms of TWIP steel, having a higher control during handle throughout the steelmaking facilities than when using forceps or toothed forceps to pressure and hold them, a more complicated and unsafe operation. In this manner, magnetic properties of this advanced TWIP steel are influenced by chemical composition and microstructure conditioning.

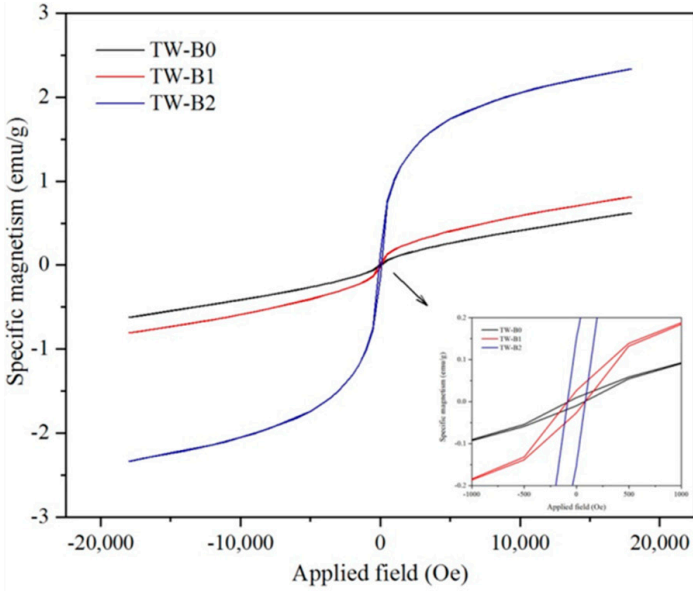

(a)

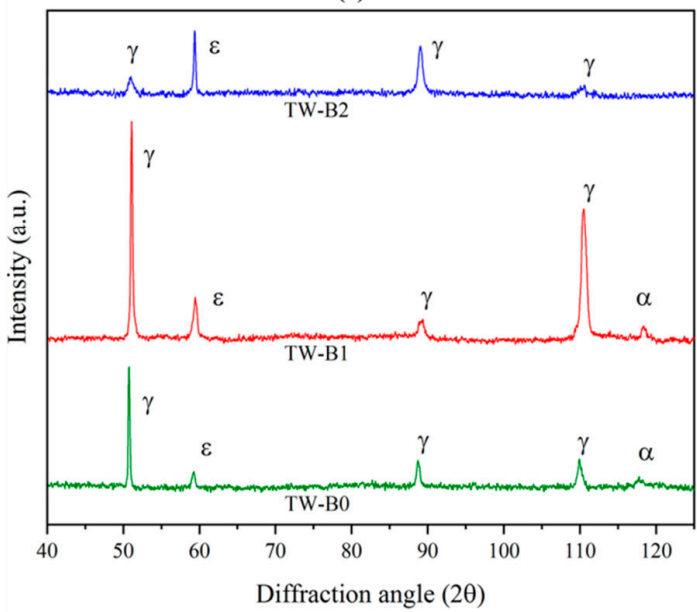

(c)

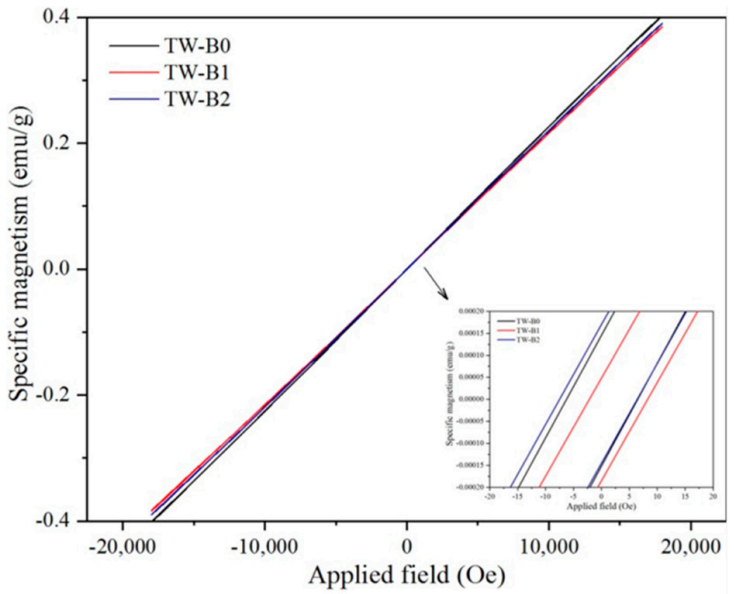

(b)

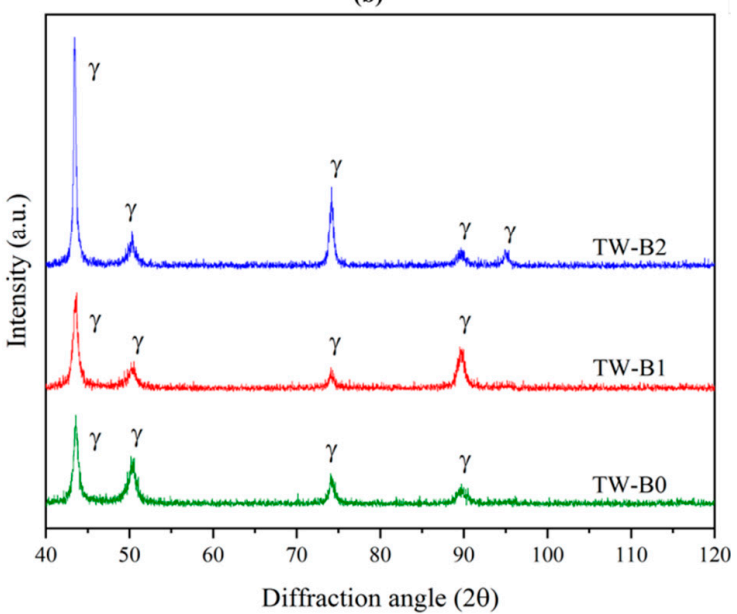

(d)

Figure 10. (a,b) Magnetic behavior of TWIP steels in the as-cast and as-cold-rolled conditions, respectively; (c,d) X-ray patterns of TWIP steels in the as-cast and as-rolled conditions, respectively.

In most cases, it is practical to detect microstructural changes by measuring magnetic properties during steel processing [40]. Moreover, several magnetic-based systems, such as pulsed electromagnetic sensors, have currently been developed and installed for monitoring microstructural and morphological changes occurring during the different stages of steel manufacturing or for detecting alterations caused by a degradation mechanism [41]. It should be noted that the degree of segregation in cast TWIP steels has promoted this magnetic manifestation, since X-ray diffraction patterns have indicated the presence of ferromagnetic phases, such as ferrite and $\varepsilon$-martensite (see Figure 10c). Therefore, magnetic effects can be induced on materials that could not become magnetic themselves. In contrast, after thermomechanical and mechanical treatment of TW-B0, TW-B1 and TW-B2 steels (i.e., hot- and cold-rolling operations), the segregation component and solidification structure were eliminated, and chemical composition was homogenized. Thus, TWIP steel shows an antiferromagnetic behavior (see Figure 10b), due to the fully austenite phase, as shown by the X-ray diffraction patterns in Figure 10d. The relative magnetic permeability in this condition is below that of the reported ones for other non-magnetic steels [42]. The important data that support the weak ferromagnetic manifestation 
or the lack of ferromagnetism behavior are in agreement with the SFE values required to ensure the twinning-induced plasticity effect. The values of SFE that were calculated by using JMatPro software were $18 \mathrm{~mJ} / \mathrm{m}^{2}$ at room temperature $\left(20^{\circ} \mathrm{C}\right)$ for the three studied steels. Table 3 summarizes obtained magnetic properties of studied TWIP steels. The normal coercive field strength $(\mathrm{Oe})$ in the as-cast condition was approximately -75 for TW-B0, -82 for TW-B1 and -85 for TW-B2.

Table 3. Obtained magnetic properties in studied TWIP steels.

\begin{tabular}{|c|c|c|c|c|}
\hline TWIP Steel & Type of Behavior & $\begin{array}{c}\text { Specific } \\
\text { Magnetization } \\
(\mathrm{emu} / \mathrm{g})\end{array}$ & $\begin{array}{c}\text { Magnetic } \\
\text { Susceptibility } \\
\left(\mathrm{m}^{3} / \mathrm{kg}\right)\end{array}$ & $\begin{array}{l}\text { Specific Remnant } \\
\text { Magnetization }\end{array}$ \\
\hline TW-B0_as cast & Weak ferromagnetic & $\approx 0.60$ & - & $\approx 0.010$ \\
\hline TW-B1_as cast & Weak ferromagnetic & $\approx 0.80$ & - & $\approx 0.026$ \\
\hline TW-B2_as cast & Ferromagnetic & $\approx 2.35$ & - & $\approx 0.150$ \\
\hline TW-B0_as rolled & Antiferromagnetic & $\approx 0.40$ & $\approx 2.51 \times 10^{-7}$ & - \\
\hline TW-B1_as rolled & Antiferromagnetic & $\approx 0.38$ & $\approx 2.51 \times 10^{-7}$ & - \\
\hline TW-B2_as rolled & Antiferromagnetic & $\approx 0.39$ & $\approx 2.51 \times 10^{-7}$ & - \\
\hline
\end{tabular}

\subsection{Mechanical Properties of Advanced TWIP Steel}

\subsubsection{Hardness Measurements in the Solidification Structure}

Figure 11 shows the variation of microhardness along the solidification structure of the TWIP steels investigated in the present work. As can be seen, the columnar zones exhibit the larger microhardness than the equiaxed zones and also than the columnar-to-equiaxed transition (CET) zone, ranging from an average value of $161.26 \mathrm{HV}_{0.5}$ for the TW-B0, $146.44 \mathrm{HV}_{0.5}$ for the TW-B10 to $156.38 \mathrm{HV}_{0.5}$ for TW-B2. This microhardness variation is associated with the effect of the larger cooling rates during solidification process [43]. On the other hand, the lower microhardness values in the equiaxed zone ranging from 153.65 $\mathrm{HV}_{0.5}$ for TW-B0, $129.81 \mathrm{HV}_{0.5}$ for TW-B1 to $137.56 \mathrm{HV}_{0.5}$ for TW-B2 are achieved due to the crystallization phenomenon that takes place during solidification in the center of the ingot. In the CET zone, the microhardness values are $156.60 \mathrm{HV}_{0.5}$ for TW-B0, $134.42 \mathrm{HV}_{0.5}$ for TW-B1 and $149.86 \mathrm{HV}_{0.5}$ for TW-B2, and they are achieved due to the change in material microstructure. As can be observed from these microhardness measurements, TW-B0 is the steel with the largest microhardness in all solidification structure zones. This effect is linked with the incoherent crystallization of dendrites and the resulting resistance of multilayered regions of fine secondary dendritic arms and the corresponding level of solute segregation. Lastly, in TW-B2, an influence of boron micro-addition can be perceived in microhardness in accordance with the larger dendritic and austenitic grain size refinement and the greater particle population when compared with TW-B1.

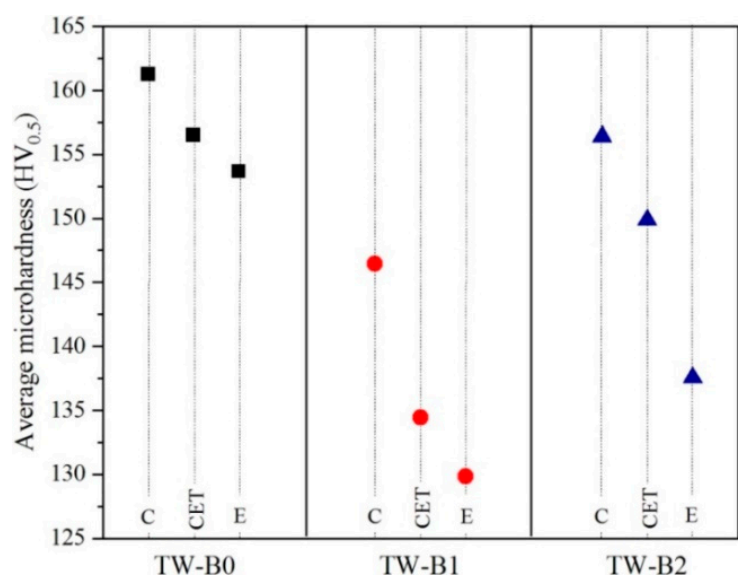

Figure 11. Average microhardness profile of studied TWIP steels in the as-cast condition. 


\subsubsection{Hot Mechanical Behavior of Advanced TWIP Steel in the As-Cast Condition}

Figure 12 shows the hot ductility behavior in the as-cast condition of the studied low-carbon highly alloyed TWIP steels microalloyed with boron, in terms of the percentage of reduction of area (\%RA) as testing temperature increases. In the case of TW-B0, the RA at the lowest testing temperature is $45.63 \%$, at the intermediate testing temperature the RA drops at $23.59 \%$ and at the highest testing temperature the RA increases to a value of $36.75 \%$. In the case of TW-B1, an improvement in the hot ductility behavior is observed, since at the lowest testing temperature the RA is $58.52 \%$, at the intermediate testing temperature the RA again drops to a value of $49.77 \%$ and at the highest testing temperature the RA continues decreasing up to $41.33 \%$. However, a noticeable enhancement of the hot ductility behavior is seen in TW-B2. Thus, at the lowest testing temperature the RA values is $65.16 \%$, at the intermediate testing temperature the RA value increases to $69.92 \%$ and then, at the highest testing temperature, the RA drops slightly to $58.11 \%$. Therefore, boron microalloying to TWIP steel improves their hot ductility behavior. When 180 ppm of boron are added to the steel (TW-B1), a small recovery is observed with respect to the observed values in the boron-free reference steel (TW-B0). It is important to mention that TW-B0 does not reach the minimum RA value of $40 \%$ required to perform hot working at the intermediate temperature range [44], especially when simulating the strengthening operation during continuous casting of steel for avoiding transverse cracking susceptibility. On the other hand, at the intermediate temperature range, TW-B1 overcomes the above mentioned required RA value. However, a constant decrease is observed in the hot ductility behavior as testing temperature increases, indicating that hot workability is not enough to carry out TWIP steel processing. Kang et al. [26] claimed that the additions of both $\mathrm{B}$ and Ti elements to a high $\mathrm{Al}$ and high $\mathrm{Al}, \mathrm{Nb}$ containing TWIP steels, transverse cracking does not represent a serious problem when continuously casting due resulting RA values range very close to the minimum required to overcome steel cracking propensity.

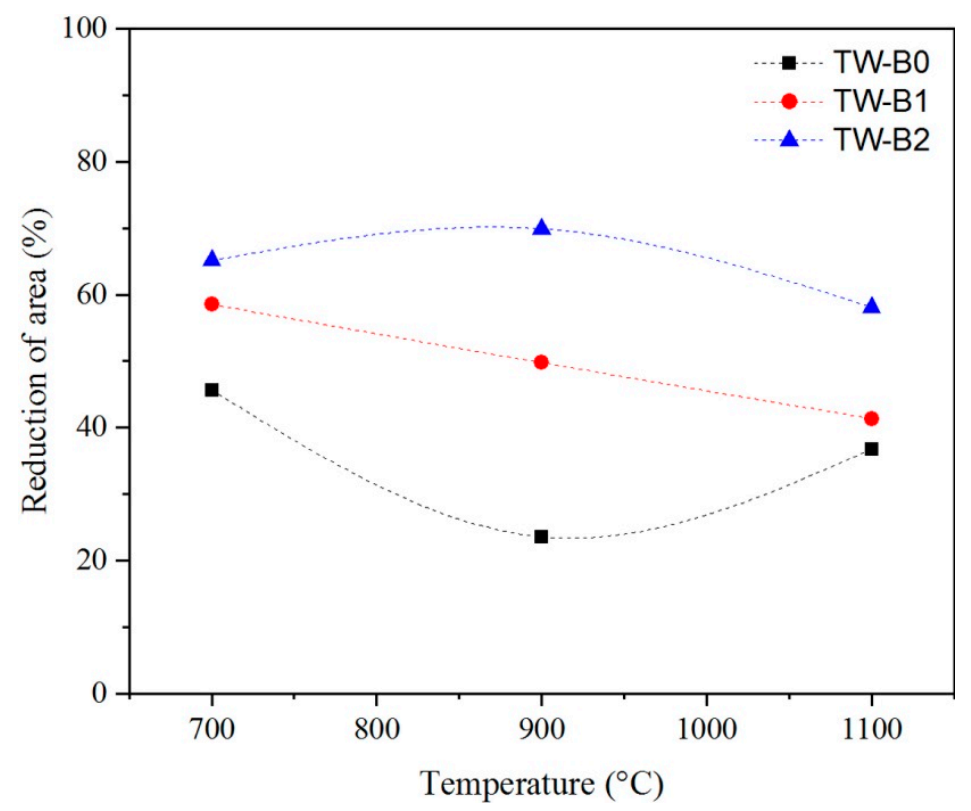

Figure 12. Hot ductility behavior of studied TWIP steels as a function of temperature.

Along testing temperature range $\left(700,900\right.$ and $\left.1100{ }^{\circ} \mathrm{C}\right)$, the best hot ductility results were obtained when $470 \mathrm{ppm}$ of boron was added to the steel. Comparing TW-B0 with TW-B1, we see that the improvement in hot ductility at $700{ }^{\circ} \mathrm{C}$ is about $22 \%$. When the comparison is made with TW-B2, the improvement is near 30\%. On the other hand, the most outstanding values of hot ductility improvement with respect to TW-B0 at $900{ }^{\circ} \mathrm{C}$ are $52 \%$ and $66 \%$ for TW-B1 and TW-B2, respectively. The greater difference between TW-B0 and TW-B2 would result in more than the triple of the hot workability during straining process at $900^{\circ} \mathrm{C}$. Lastly, at $1100^{\circ} \mathrm{C}$, the ductility improvement ranges from about 
$11 \%$ for TW-B1 and around 36\% for TW-B2 when compared with TW-B0. It is noteworthy that the hot ductility behavior of this highly alloyed TWIP steel, fabricated with commercial raw materials, and microalloyed with a higher boron content (470 ppm) behaves similarly to high-purity Fe-Mn-C, Fe-Mn-C-Al and Fe-Mn-C-Al-Si systems reported in the literature [21-23,26] at the intermediate temperature range. Therefore, as chemistry is enhanced in the fabrication of TWIP steels, it has been shown an improvement in the hot ductility at intermediate testing temperatures $\left(\approx 900{ }^{\circ} \mathrm{C}\right)$, and also it has been identified that TWIP steels do not recover the hot ductility at lower or higher temperatures, as observed typically in other steel grades. In other steel grades (e.g., high strength low alloy (HSLA) microalloyed steels), there is a definite ductility through ranging from 700 to $1100{ }^{\circ} \mathrm{C}$, and in which, at lower and a higher testing temperatures, hot ductility typically recovers. However, TWIP steels cannot be compared with the above-cited ductility valley of those steels that experiment phase transformation.

According to Mejía et al. [21], a conservative value of $60 \%$ in RA at intermediate temperatures in the range of $800-900{ }^{\circ} \mathrm{C}$ can be taken as a good hot ductility criterion in high-Mn TWIP steels due their intrinsic nature in influencing hot workability. Thus, the good ductility in the intermediate temperature range in this type of boron-containing advanced high-strength austenitic (TWIP) steels has been attributed to dynamic recrystallization (DRX) taking place during hot working, where boron atoms encourage the hot plastic flow by a solute drag effect carrying out at grain boundaries, enhancing austenitic grain cohesion and preventing microvoid nucleation and microcrack propagation [21]. In this sense, it can be said that both solidification structure and austenitic grain sizehave benefited the hot ductility behavior in TW-B2. Moreover, it has been claimed that columnar and equiaxed zones need to be as finer for improving the hot ductility of TWIP steels [11]. Coarse columnar grain size promotes intergranular failure propensity due to the greater stress concentration at crack tip during plastic deformation. For comparative purposes, Figure 13 shows the fracture surface micrographs at low SEM magnification of studied TWIP steels strained to fracture at the intermediate temperature range of $900{ }^{\circ} \mathrm{C}$. Besides that, it is important to mention that tensile samples for hot ductility studies were taken from the columnar zone for simulating the unbending operation in the continuous casting process. In the three steels, after hot tensile testing, a remaining dendritic appearance component of the columnar zone is observed in the fracture surface. This fracture condition is better identified in the case of TW-B0 steel, which has the lowest value of \%RA, presenting a brittle failure. TW-B1 steel also exhibits brittle fracture; however, TW-B2 steel, which has the better hot ductility behavior, presents a ductile fracture containing many dimples, and some brittle regions are observed, too, in which grain boundary sliding and de-cohesion occurred. A detailed explanation of the mechanisms taking place in fracture of hot-tensile TWIP steels can be found elsewhere [21].

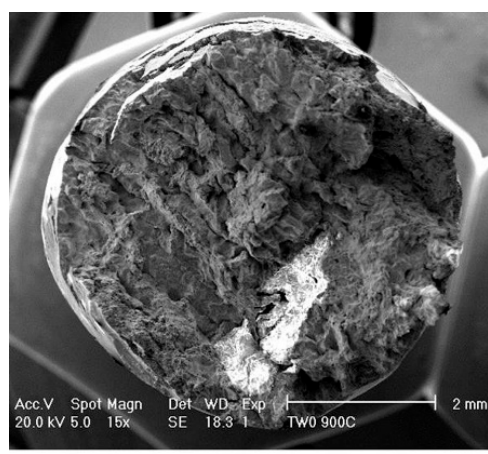

(a)

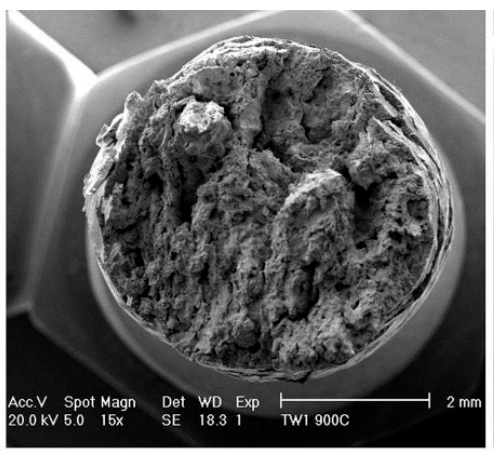

(b)

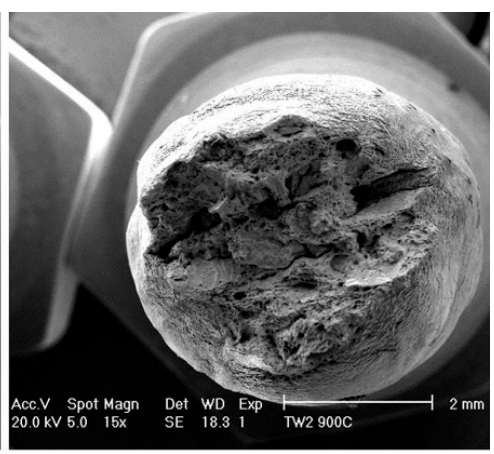

(c)

Figure 13. Fracture surface appearance of hot-tensile-tested TWIP steels showing a remaining solidification structure component after testing at $900{ }^{\circ} \mathrm{C}$ : (a) TW-B0, (b) TW-B1 and (c) TW-B2. 


\section{Conclusions}

The results of the present investigation show the effects of boron micro-additions (180 and $470 \mathrm{ppm}$ ) in an advanced low-carbon highly alloyed TWIP steel on the solidification structure development, magnetic properties and hot ductility behavior in the as-cast condition. Main conclusions are as follow:

(1) Calculations using JMatPro software show that boron micro-addition to TWIP steel reduces the solidus temperature at which the steel solidification is completed, from $1312.78{ }^{\circ} \mathrm{C}$ for the steel without boron content to $1190{ }^{\circ} \mathrm{C}$ for the steel with the highest boron content (470 ppm). The larger the liquid-to-solid zone is, the higher the degree of crystallization of the equiaxed grains by an inoculation mechanism as the amount of rejected solute elements in melt increases. This effect causes refinement of the overall solidification structure.

(2) Boron-free TWIP steel exhibits an incoherent dendritic crystallization in both columnar and equiaxed zones, developing a type of multilayered (austenite + ferrite) microstructure in the secondary dendritic arms. However, TWIP steel microalloyed with boron (180 and 470 ppm) causes a well-developed side-branched morphology of dendritic microstructures in both columnar and equiaxed zones.

(3) As boron content increases in the TWIP steel, a refining effect in the columnar and equiaxed solidification structure is observed. Dendritic measurements revealed that the average length of primary dendritic arms in the columnar zone corresponds to $766.66 \mu \mathrm{m}$ for TW-B0, $705.71 \mu \mathrm{m}$ for TW-B1 and $601.25 \mu \mathrm{m}$ for TW-B2. In the same manner, the CET zone is reduced in the ingot from 10 to $6 \mathrm{~mm}$ as boron content increases. This behavior in solidification structure causes a larger equiaxed zone, refining also the austenitic grain size from 770.09 to $577.20 \mu \mathrm{m}$ and from 531.86 to $344 \mu \mathrm{m}$ in both columnar and equiaxed zones as boron content increases too, respectively.

(4) In the as-cast condition, a ferromagnetic behavior was recognized in the TWIP steel as boron content increases. This magnetic manifestation is attributed to the presence of phases such as ferrite and $\varepsilon$-martensite formed due segregation, which have been identified by X-ray diffraction tests. In contrast, after hot- and cold-rolling, a fully austenitic phase is obtained in the steel, and the ferromagnetic behavior disappears.

(5) Boron microalloying to the present low-carbon highly alloyed TWIP steel is beneficial for the hot ductility behavior. The greatest influence was observed for the higher concentration of boron (470 ppm), where a value near to 70\% in RA was obtained. In comparison with the steel without boron micro-addition, the increase in hot ductility improvement in terms of RA is more than triple at the intermediate testing temperature range $\left(900^{\circ}\right)$.

(6) Notwithstanding boron improves the hot ductility, the fact of adding only 180 ppm of boron to the steel does not reflect any benefit, because there is a strong trend in lowering the \% RA as testing temperature increases.

Author Contributions: Conceptualization, A.E.S.-R., G.A.-G., J.F.C.-A. and A.B.-P.; funding acquisition, A.E.S.-R.; investigation, A.E.S.-R., G.A.-G. and I.A.F.; methodology, J.F.C.-A., R.D.-L., A.S., F.S.-D.J. and A.M.B.-M.; writing —original draft, A.E.S.-R.; writing-review and editing, G.A.-G. and A.B.-P. All authors have read and agreed to the published version of the manuscript.

Funding: This research work was supported by UNAM-PAPIIT, Grant No. IA104219.

Acknowledgments: The authors are grateful for valuable technical support of G.E. López-Velazco (FQ-UNAM), G. González-Mancera (FQ-UNAM), C. Flores-Morales (IIM-UNAM), A. Tejeda (IIM-UNAM), G. Lara-Rodriguez (IIM-UNAM), S. García-Galán (FQ-UNAM) and G. Arámburo-Pérez (FQ-UNAM). Fabrication of TWIP steels was carried out in the installations of DIM-IPN by I. Guadarrama-Hernández and F. Gutiérrez-López, which is particularly acknowledged. The authors also thank the technical support of Ing. Manuel García Tellez and Ing. David Cruz Cortés from PetroServcios Company-Mexico.

Conflicts of Interest: The authors declare no conflict of interest. 


\section{References}

1. Yanushkevich, Z.; Belyakov, A.; Haase, C.; Molodov, D.A.; Kaibyshev, R. Structural/Textural changes and strengthening of an advanced high-Mn steel subjected to cold rolling. Mater. Sci. Eng. A 2016, 651, 763-773. [CrossRef]

2. Bouaziz, O.; Allain, S.; Scott, C.P.; Cugy, P.; Barbier, D. High manganese austenitic twinning induced plasticity steels: A review of the microstructure properties relationships. Curr. Opin. Solid State Mater. Sci. 2011, 15, 141-168. [CrossRef]

3. Hallstedt, B.; Khvan, A.V.; Lindahl, B.B.; Selleby, M.; Liu, S. PrecHiMn-4-A thermodynamic database for high-Mn steels. Calphad 2017, 56, 49-57. [CrossRef]

4. Park, J.; Kim, J.S.; Knag, M.; Sohn, S.S.; Cho, W.T.; Kim, H.S.; Lee, S. Tensile property improvement of TWIP-cored three-layer steel sheets fabricated by hot-roll-bonding with low-carbon steel or interstitial-free steel. Sci. Rep. 2017, 7, 40231. [CrossRef]

5. Li, K.W.; Zhuang, C.L.; Liu, J.H.; Shen, S.B.; Ji, Y.L.; Han, Z.B. Smelting and casting technologies of Fe-25Mn-3Al-3Si twinning induced plasticity steel for automobiles. J. Iron Steel Res. Int. 2015, 22, 75-79. [CrossRef]

6. Yang, J.; Wang, Y.N.; Ruan, X.M.; Wang, R.Z.; Zhu, K.; Fan, Z.J.; Wang, Y.C.; Li, C.B.; Jiang, X.F. Effects of manganese content on solidification structures, thermal properties, and phase transformation characteristics in Fe-Mn-Al-C steels. Metall. Mater. Trans. B 2015, 46, 1365-1375. [CrossRef]

7. Essoussi, H.; Ettaqi, S.; Essadiqi, E. The effect of alloying elements on the stacking fault energy of a TWIP steel. Procedia Manuf. 2018, 17, 129-134. [CrossRef]

8. Zhao, L.; Van Dijk, N.H.; Lefering, A.J.E.; Sietsma, J. Magnetic detection of small fractions of ferromagnetic martensite within the paramagnetic austenite matrix of TWIP steel. J. Mater. Sci. 2013, 48, 1474-1479. [CrossRef]

9. Li, C.S.; Xu, X.F.; Ma, B.; Yao, C.G.; Wang, M. Experimental research on non-magnetic steel 30Mn27Al4V. Adv. Mat. Res. 2012, 479-481, 147-155. [CrossRef]

10. Lan, P.; Tang, H.; Zhang, J. Solidification microstructure, segregation, and shrinkage of Fe- Mn-C twinning-indiced plasticity steel by simulation and experimentation. Metall. Mater. Trans. A 2016, 47, 2964-2984. [CrossRef]

11. Lan, P.; Song, L.; Du, C.; Zhang, J. Analysis of solidification microstructure and hot ductility of Fe-22Mn-0.7C TWIP steel. Mater. Sci. Technol. 2014, 30, 1297-1304. [CrossRef]

12. Wang, D.; Wang, K.; Man, J.; Yang, J.; Han, F. Mechanical behavior and microstructure characteristics of directionally solidified TWIP steel. Metall. Mater. Trans. A 2016, 47, 3423-3434. [CrossRef]

13. Wang, D.; Wang, K.; Shi, Z.; Han, F. The mechanical and deformation behavior of TWIP steel prepared by directional solidification. Mater. Sci. Forum 2014, 783-786, 761-765. [CrossRef]

14. Wang, K.; Wang, D.; Han, F. Effect of crystalline grain structures on the mechanical properties of twinning-induced plasticity steel. Acta Mech. Sin. 2016, 32, 181-187. [CrossRef]

15. Salas-Reyes, A.E.; Mejía, I.; Cabrera, J.M. Effect of Ti microaddition on cavitation behavior during uniaxial hot-tensile of Fe-22Mn-1.5Al-1.3Si-0.5C austenitic TWIP steel. Mater. Res. Soc. Symp. 2016, 1812, $123-128$. [CrossRef]

16. De Cooman, B.C.; Estrin, Y.; Kim, S.K. Twinning-induced plasticity (TWIP) steels. Acta Mater. 2018, 142, 283-362. [CrossRef]

17. Mintz, B.; Crowther, D.N. Hot ductility of steels and its relationship to the problem of transverse cracking in continuous casting. Int. Mater. Rev. 2010, 55, 168-196. [CrossRef]

18. Wang, Y.N. Solidification structure, non-metallic inclusions and hot ductility of continuously cast high manganese TWIP steel slab. ISIJ Int. 2019, 59, 872-879. [CrossRef]

19. Altamirano-Guerrero, G.; Mejía, I.; Hernández-Exposito, A.; Cabrera, J.M. Effect of boron on the continuous cooling transformation kinetics in a low carbon advanced ultra-high strength steel (A-UHSS). MRS Proc. 2012, 1485, 83-88. [CrossRef] 
20. Mejía, I.; Altamirano-Guerrero, G.; Bedolla-Jacuinde, A.; Cabrera, J.M. Modeling of the hot flow behavior of advanced ultra-high strength steel (A-UHSS) microalloyed with boron. Mater. Sci. Eng. A 2014, 610, 116-125. [CrossRef]

21. Mejía, I.; Salas-Reyes, A.E.; Calvo, J.; Cabrera, J.M. Effect of Ti and B microadditions on the hot ductility behavior of a high-Mn austenitic Fe-23Mn-1.5Al-1.3Si0.5C TWIP steel. Mater. Sci. Eng. A 2015, 648, 311-329. [CrossRef]

22. Kang, S.E.; Banerjee, J.R.; Tuling, A.S.; Mintz, B. Influence of B on hot ductility of high Al, TWIP steels. Mater. Sci. Technol. 2014, 30, 486-494. [CrossRef]

23. Kang, S.E.; Banerjee, J.R.; Tuling, A.S.; Mintz, B. Influence of $\mathrm{P}$ and $\mathrm{N}$ on hot ductility of high $\mathrm{Al}$, boron containing TWIP steels. Mater. Sci. Technol. 2014, 30, 1328-1335. [CrossRef]

24. Reyes-Calderón, F.; Mejía, I.; Boulaajaj, A.; Cabrera, J.M. Effect of microalloying elements (Nb, V and Ti) on the hot flow behavior of high-Mn austenitic twinning induced plasticity (TWIP) steel. Mater. Sci. Eng. A 2013, 560, 552-560. [CrossRef]

25. Kim, R.; Bae, C.; Ha, Y.M.; Kim, J. Effect of titanium addition on high temperature workability of high manganese austenitic steel. ISIJ Int. 2018, 58, 535-541. [CrossRef]

26. Kang, S.E.; Banerjee, J.R.; Maina, E.M.; Mint, B. Influence of B and Ti on hot ductility of high Al and high Al, $\mathrm{Nb}$ containing TWIP steels. Mater. Sci. Technol. 2013, 29, 1225-1232. [CrossRef]

27. Li, C.; Li, F.; Liang, J.; Cao, R.; Zhao, Z. Microstructural evolution and strain hardening mechanism of a boron-containing metastable austenitic steel. Mater. Sci. Technol. 2019, 35, 2013-2023. [CrossRef]

28. Li, Q.; Liu, W. Effect of boron on hot ductility and room-temperature tensile properties of microalloyed steels with titanium and niobium. Materials 2019, 12, 2290. [CrossRef]

29. Dong, Y.; Sun, Z.; Xia, H.; Feng, J.; Du, J.; Fang, W.; Liu, B.; Wang, G.; Li, L.; Zhang, X.; et al. The influence of warm rolling reduction on microstructure evolution, tensile deformation mechanism and mechanical properties of an Fe -30Mn-4Si-2Al TRIP/TWIP steel. Metals 2018, 8, 742. [CrossRef]

30. Salas-Reyes, A.E.; Altamirano-Guerrero, G.; Flores-Álvarez, J.F.; Chávez-Alcalá, J.F.; Salinas, A.; Figueroa, I.A.; Rodriguez-Lara, G. Influence of the as-cast and cold rolled microstructural conditions over corrosion resistance in an advanced TWIP steel microalloyed with boron. J. Mater. Res. Technol. 2020, 9, 4034-4043. [CrossRef]

31. PetroServicios. Available online: http://www.petroservicios.com.mx (accessed on 29 June 2020).

32. Wilson, F.G.; Gladman, T. Aluminum nitride in steel. Int. Mater. Rev. 1988, 33, 221-286. [CrossRef]

33. Takaki, S.; Fujioka, M.; Aihara, S.; Nagataki, Y.; Yamashita, T.; Sano, N.; Adachi, Y.; Nomura, M.; Yaguchi, H. Effect of copper on tensile properties and grain-refinement of steel and its relation to precipitation behavior. Mater. Trans. 2004, 45, 2239-2244. [CrossRef]

34. Komazaki, S.; Koyama, A.; Misawa, T. Effect of morphology of copper precipitation particles on hydrogen embrittlement behavior in Cu-added ultra low carbon steel. Mater. Trans. 2002, 43, 2213-2218. [CrossRef]

35. Kurz, W.; Fisher, D.J.; Trivedi, R. Progress in modelling solidification microstructures in metals and alloys: Dendrites and cells from 1700 to 2000. Int. Mater. Rev. 2018, 64, 311-354. [CrossRef]

36. Hamada, A.S.; Karjalainen, L.P. Hot ductility behavior of high-Mn TWIP steels. Mater. Sci. Eng. A 2011, 528, 1819-1827. [CrossRef]

37. Wang, T. Multi-dimensional characterization and controlling of microstructure evolution during solidification of metallic alloys. IOP Conf. Ser. Mater. Sci. Eng. 2019, 580, 012013. [CrossRef]

38. Mendoza, R.; Alkemper, J.; Voorhess, P.W. The morphological evolution of dendritic microstructures during coarsening. Metall. Mater. Trans. A 2003, 34, 481-489. [CrossRef]

39. Jahazi, M.; Jonas, J.J. The non-equilibrium segregation of boron on original and moving austenite grain boundaries. Mater. Sci. Eng. A 2002, 335, 49-61. [CrossRef]

40. San Martin, D.; van Dijk, N.H.; Jiménez-Melero, E.; Kampert, E.; Zeitler, U.; van der Zwaag, S. Real-time martensitic transformation kinetics in maraging steel under high magnetic fields. Mater. Sci. Eng. A 2010, 527, 5241-5245. [CrossRef]

41. Mesina, M.B.; de Jong, T.P.R.; Dalminj, W.L. Scrap stainless steel detection using a pulsed electromagnetic field. Int. J. Miner. Process. 2005, 76, 21-31. [CrossRef]

42. Cao, J.L.; Zhao, A.M.; Liu, J.X.; He, J.G.; Ding, R. Effect of Nb on microstructure and mechanical properties in non-magnetic high manganese steel. J. Iron Steel Res. Int. 2014, 21, 600-605. [CrossRef] 
43. Wang, B.; Zhong, H.; Li, X.; Wang, T.; Wu, T.; Liu, Q.; Zhai, Q. Thermal simulation study on the solidification structure and segregation of a heavy heat-resistant steel casting. Metals 2019, 9, 249. [CrossRef]

44. Mintz, B. The influence of composition on the hot ductility of steels and to the problem of transverse cracking. ISIJ Int. 1999, 39, 833-855. [CrossRef] 